Change in Anti-COVID-19 Behavior and Prejudice against Minorities during the COVID19 Pandemic: Longitudinal Evidence from Five European Countries

Running head: Change in Anti-COVID-19 Behavior and Prejudice during the Pandemic

Tibor Zingora, ${ }^{1 *}$ Michèle D. Birtel, ${ }^{2}$ Sylvie Graf, ${ }^{1,3}$ Martina Hrebickova, ${ }^{1}$ David Lacko, ${ }^{1}$ Mirjana Rupar, ${ }^{1,4}$ Jaroslav Tocik, ${ }^{1} \&$ Shpend Voca ${ }^{5}$

[This is a preprint version.]

\author{
${ }^{1}$ Institute of Psychology, Czech Academy of Sciences, Czechia \\ ${ }^{2}$ Institute for Lifecourse Development, University of Greenwich, UK \\ ${ }^{3}$ Institute of Psychology, University of Bern, Switzerland \\ ${ }^{4}$ Institute of Psychology, Jagiellonian University, Poland \\ ${ }^{5}$ Faculty of Psychology, AAB College, Kosovo
}

*Corresponding author: Tibor.Zingora@psu.cas.cz 


\begin{abstract}
:
During a pandemic, it is vital to identify factors that motivate individuals to behave in ways that limit virus transmission (i.e., anti-COVID-19 behavior). Fear has been suggested to motivate health-oriented behavior, yet fear of the virus (i.e., fear of COVID-19) could have unintended consequences, such as an increase in anti-immigrant prejudice. In a three-wave longitudinal study $\left(\mathrm{N}_{\mathrm{T} 1}=4275\right)$ in five European countries from April to October 2020, we investigated how social norms, the impact of the pandemic on individuals, and intergroup contact affected fear of COVID-19 and - or in turn - anti-COVID-19 behavior and prejudice towards immigrants. A latent change score model - distinguishing between intra- and inter-individual changes in outcomes - indicated that fear of COVID-19 influenced neither anti-COVID-19 behavior nor prejudice. Anti-COVID-19 behavior was increased by anti-COVID-19 norms (i.e., belief that others perform anti-COVID-19 behaviors), while prejudice was influenced by positive and negative direct and mass-mediated intergroup contact.
\end{abstract}

Keywords: pandemic, prejudice, behavior, intergroup contact, norms 


\section{Change in Anti-COVID-19 Behavior and Anti-Immigrant Prejudice during the COVID-19 Pandemic: Longitudinal Evidence from Five European Countries}

The impact of the COVID-19 pandemic on the quality of people's lives - in terms of health deterioration or economic consequences - has been unprecedented in recent history. For example, states of the European Union (EU) closed their borders for the first time, and the EU's recovery plan has exceeded $€ 2$ trillion (European Commission, 2021). A crucial strategy to reduce the spread of COVID-19 is adopting behaviors that can limit COVID-19 transmission (i.e., anti-COVID-19 behavior). Consequently, anti-COVID-19 behavior does not only decrease individual chances of getting infected but adds up to a collective effort to limit the spread of the virus within the whole society (Block et al., 2020). Anti-COVID-19 behavior comprises various actions such as social distancing, wearing protective aids, or supporting governmental recommendations or restrictions aimed at fighting the pandemic.

One factor that has been widely used to motivate health-related behavioral change, including anti-COVID-19 behavior, is fear (Stolow et al., 2020). Preliminary (i.e., crosssectional) evidence showed positive associations between fear of COVID-19 and anti-COVID-19 behavior (Håkansson \& Claesdotter, 2021). Yet, despite the evidence that fear does not automatically induce compliance with health-oriented behavior, authorities often employ fear appeals to increase the willingness of the general public to respond to threatening situations (Kok et al., 2014; Stolow et al., 2020). This is problematic also because fear can have numerous other, unintended consequences for relevant domains of societies—-such as an increase in antiimmigrant prejudice (Bavel et al., 2020), through, for example, the belief that these groups may transmit foreign pathogens (Schaller \& Park, 2011). Although fear can have positive effects (i.e., an increase in health-oriented behavior) there are also negative effects of fear (i.e., deterioration 
of intergroup relations). A simultaneous investigation of both effects has not been carried out so far.

Importantly, simultaneous intra-individual changes in anti-COVID-19 behavior and prejudice may only appear to be related due to third unaccounted factors (e.g., time-invariant or stable traits) as indicated by the inter-individual effects (Hounkpatin et al., 2018; Klopack \& Wickrama, 2020; Li \& Wang, 2022), not due to an effect of fear of COVID-19. In order to be sure whether one variable indeed induces changes in a second variable within an individual, it is necessary to distinguish the inter-individual from the intra-individual effects. While intraindividual effects represent the influence of predictors on changes in anti-COVID-19 behavior and prejudice - the focus of our research — inter-individual effects indicate that two variables are merely correlated but otherwise causally or developmentally unrelated (Hounkpatin et al., 2018; Klopack \& Wickrama, 2020; Li \& Wang, 2022).

The focal outcomes of our research that relate to critical aspects of societies amidst a pandemic, namely anti-COVID-19 behavior and prejudice, are shaped by other relevant factors beyond fear of COVID-19. By combining literature on change in health-oriented behavior and on the psychology of intergroup relations, we derived factors influencing fear of COVID-19, which could in turn influence anti-COVID-19 behavior and prejudice. Specifically, social norms based on behavior perceived in one's social environment, the impact of the pandemic on people's lives, and various forms of both positive and negative intergroup contact - direct or mass-mediated that could affect the potentially detrimental effects of fear of COVID-19 on increase in prejudice.

\section{The Effect of Fear of COVID-19 on Anti-COVID-19 Behavior}

Changes in anti-COVID-19 behavior and prejudice can be intertwined via other COVID19 related variables, particularly fear of COVID-19. Yet, while an increase in anti-COVID-19 
behavior following fear of COVID-19 is desirable, an increase in prejudice is not. To this end, we combined and tested predictions drawn from the Fear-Appeal Theory about a positive link between fear of COVID-19 and anti-COVID-19 behavior (e.g., the Extended Parallel Process model; Witte \& Allen, 2000) and predictions about a positive link between fear of COVID-19 and prejudice (e.g., Behavioral Immune System model; Schaller \& Neuberg, 2012).

Fear of disease is linked to behaviors that limit the chances of getting the disease (Epstein et al., 2008). In line with fear appeal theories, campaigns aimed at facilitating anti-COVID-19 behavior could be more effective if they increase fear of COVID-19, especially under certain conditions (e.g., when the threat seems manageable; Witte \& Allen, 2000). Based on crosssectional data, fear of COVID-19 was associated with anti-COVID-19 behavior (Håkansson \& Claesdotter, 2021; Harper et al., 2020; Jørgensen et al., 2021). Although fear appeals are common means to promote health-oriented behavior, there is evidence suggesting undesirable side-effects of campaigns using such "scare tactics" (Stolow et al., 2020). Stimulating fear may not lead to health-oriented behaviors, especially when coupled with high threat and low selfefficacy (Peters et al., 2013). Exactly these conditions apply to pandemics when the widespread virus is highly threatening, and for its eradication coordinated efforts of the whole population are inevitable. Moreover, the quality of studies on fear appeals in promoting health-oriented behaviors has been criticized due to a lack of research that would capture behavioral change, which limits our understanding of the causal relationship between fear appeal and behavior (Kok et al., 2018). Especially in the context of the pandemic, the existing evidence is limited to individual countries, employing cross-sectional design, and not distinguishing inter- and intraindividual changes (c.f., Legate et al., 2022). In conclusion, it remains unclear whether the fear 
of a virus predicts behaviors that should limit virus transmission, crucially on the intra-individual level.

\section{The Effect of Fear of COVID-19 on Prejudice}

Except for its potential positive effect on anti-COVID-19 behavior, fear of COVID-19 can simultaneously have a disruptive effect on intergroup relations (Bavel et al., 2020). A societal threat in general (Feldman \& Stenner, 1997; Jackson et al., 2019) and fear of a disease, in particular, could worsen intergroup relations (e.g., in line with pathogen-prevalence hypothesis; Faulkner et al., 2004; Kim et al., 2016; Prati \& Pietrantoni, 2016; Schaller \& Neuberg, 2012). Multiple theoretical accounts predict that fear of COVID-19 could facilitate prejudice. Theoretical models rooted in the evolutionary perspective surmise that people have developed strategies that decrease the chances of transmitting a virus. According to the Behavioral Immune System model (BIS; Schaller \& Neuberg, 2012), people react to cues suggesting the presence of pathogens with increases in prejudice, ethnocentrism, or xenophobia. In these accounts, outgroup members were suggested to be seen as a potential source of infection transmitting novel pathogens. Fear of disease should therefore motivate negative outgroup reactions, such as outgroup avoidance or prejudice (Fincher \& Thornhill, 2008; Meleady et al., 2021). This tendency should emerge especially if the outgroup is perceived as foreign (Faulkner et al., 2004). Immigrants from the Middle east are a highly salient outgroup that have been the focus of public discourse in Europe, and as such were chosen as a target group for our research on the change in prejudice during the beginning of the COVID-19 pandemic.

Another theoretical account containing relevant predictions for the link between fear of COVID-19 and prejudice is the terror management theory, arguing that the fear of death brought on by the COVID-19 pandemic alters attitudes and behavior (Pyszczynski et al., 2021). Next, the 
intergroup threat theory puts forward that prejudice is increased by threats perceived by outgroup members (Riek et al., 2006; Stephan et al., 2009). During health crises, such perception of threats could be further enhanced by the danger of virus transmission by immigrants, ultimately leading to increased prejudice. Moreover, according to the cognitive scarcity theory, environmental stressors, such as disease threats, negatively influence cognitive functioning and could lead to hostility towards outgroups (Daniels et al., 2021; Mani et al., 2013).

Despite these theories suggesting a link between fear of COVID-19 and prejudice, empirical evidence is mixed. Perceived sensitivity to pathogen threat did not predict outgroup prejudice or outgroup social distancing in British adults during the COVID-19 pandemic (Meleady et al., 2021). Importantly, in this very study, disgust sensitivity—which was expected to be associated with the avoidance of COVID-19—-predicted social distancing towards both outgroup and ingroup, implying its association with social distancing from people in general, not from outgroups in particular. In a similar vein, California adults' prejudice against Asian Americans did not increase after being primed with questions about the COVID-19 pandemic (Daniels et al., 2021). Similarly, support for a diverse society in Germany did not differ between times of higher vs. lower incidence of COVID-19 (Drouhot et al., 2021), and pathogenavoidance tendencies were not associated with attitudes towards foreigners in Japan (Yamagata et al., 2020). Moreover, experimental manipulation of pathogen threat did not increase prejudice against a minimal group in participants from the US (Makhanova et al., 2022). In contrast, a cross-sectional study suggests that fear of COVID-19 has both enhancing and reducing effects on prejudice (Adam-Troian \& Bagci, 2021). Specifically, cross-sectional data from Turkish respondents showed that the positive indirect association between fear of COVID-19 and prejudice against Syrian refugees through fear of Syrian refugees was stronger than the negative 
indirect association between fear of COVID-19 and prejudice through common ingroup identification with Syrian refugees. This geographically-constrained cross-sectional evidence implies that an increase in prejudice as a result of threat should be larger than a decrease in prejudice due to common ingroup identification. Critically, forming a common ingroup identification can be challenging in the case of geographically distant and unfamiliar groups (e.g., immigrants from the Middle East in Europe) that are perceived as more different than citizens of a neighboring country (i.e. Syrian refugees in Turkey).

Previous studies brought first insights into the predictors of prejudice in the context of the COVID-19 pandemic in general and into the role of fear of COVID-19 in particular, whereby COVID-19 related variables were usually unrelated to prejudice (c.f., Adam-Troian \& Bagci, 2021). Nevertheless, previous research was mostly cross-sectional (Adam-Troian \& Bagci, 2021; Alston et al., 2020; Håkansson \& Claesdotter, 2021; Jørgensen et al., 2021; Meleady et al., 2021), making it impossible to draw conclusions about relationships between variables over time. Moreover, although most above-mentioned theories (e.g., the BIS; Schaller \& Park, 2011), predict intra-individual changes in prejudice, the employed analytical approaches rarely separate intra- from inter-individual changes.

Anti-COVID-19 Norms and Impact of the Pandemic as Predictors of Anti-COVID-19

\section{Behavior and Prejudice}

The focal effect of fear of COVID-19 on anti-COVID-19 behavior and prejudice is likely to be influenced by other relevant factors in the situation of a global pandemic. Complex and new situations are difficult to navigate and, thus, people tend to rely on cues from their social environment—such as descriptive norms that help guide behavior (Hardin \& Conley, 2001). In line with social identity theory (Terry \& Hogg, 1996), social norms shape attitudes and 
behaviors; in the pandemic context, anti-COVID-19 norms - or perceptions of how others behave with respect to limiting virus transmission—could directly stimulate anti-COVID-19 behavior. Social norms become even more important in the presence of danger represented, for example, by the COVID-19 pandemic (Fritsche et al., 2011; Giannakakis \& Fritsche, 2011; Jonas et al., 2008). Except for this direct link between anti-COVID-19 norms and anti-COVID19 behavior, anti-COVID-19 norms can shape anti-COVID-19 behavior also indirectly through fear of COVID-19. Anti-COVID-19 behavior observed among ingroup members communicates the severity of COVID-19 perceived by the ingroup. This is likely to impact individuals' perception of COVID-19 as threatening since people generally tend to share beliefs with others (Hardin \& Conley, 2001). Consequently, fear of COVID-19 could not only mediate an effect of anti-COVID-19 norms on anti-COVID-19 behavior but also create a link to an otherwise unrelated factor - prejudice.

Although the COVID-19 pandemic has influenced everyone, people's lives have been affected to a different extent. People who were more affected by COVID-19 could be more motivated to stop the spread of the virus and, thus, perform anti-COVID-19 behavior more consequently than those less affected. For this reason, we have included the impact of the pandemic on health, social and economic aspects of individuals' life, and the lives of people in their close social circle as another predictor of anti-COVID-19 behaviors. Since the personal relevance of a threat was shown to evoke a larger fear response (Stussi et al., 2015), we expected that the impact of the pandemic on an individual would also influence fear of COVID-19. In line with this argumentation, the perceived risk of COVID-19, such as the risk for loved ones, was found to be correlated with fear of the virus (Mertens et al., 2020). 
In sum, based on the presented theoretical rationale, we included both anti-COVID-19 norms and the individual impact of the pandemic as relevant predictors of fear of COVID-19 and anti-COVID-19 behavior. Since fear of COVID-19 should affect both anti-COVID-19 behavior and prejudice, we expected that both anti-COVID-19 norms and the impact of the pandemic on individuals would exercise an indirect effect on prejudice through fear of COVID-19.

\section{Change in Prejudice in the Context of a Pandemic}

Generally, past evidence warns against an increase in prejudice toward social minorities during crises, such as the 2008 financial crisis, especially if their causes are attributed to minority groups (Becker et al., 2011). Specifically, in the context of pandemics, intergroup hostility pointing to an increase in prejudice was observed in the past, although the evidence is mixed (Cohn, 2015). The COVID-19 pandemic could be particularly linked to an increase in prejudice against ethnic outgroups because its outburst has been associated with China, framing the pandemic in an intergroup context. Indeed, connecting China or Asia with COVID-19 was associated with prejudice and xenophobia (Croucher et al., 2020; Hu et al., 2020; Jakovljevic et al., 2020; Mandalaywala et al., 2020; Rzymski \& Nowicki, 2020; Tabri et al., 2020; Tsai et al., 2020; Zeng et al., 2020). The potential impact of the COVID-19 pandemic on increasing prejudice does not only concern groups directly associated with the virus (e.g., Chinese people) but also other groups. According to the pathogen-prevalence hypothesis and the Behavioral Immune System model, the high prevalence of pathogens could increase generalized xenophobia and outgroup avoidance (Murray et al., 2011, 2013; Schaller \& Park, 2011). Consequently, all immigrants arriving from outside could be perceived as more likely to carry the disease than ingroup members, which can enhance anti-immigrant prejudice in general (Faulkner et al., 2004). Ethnic groups that were already stigmatized and negatively perceived prior to the pandemic, such 
as immigrants from the Middle East employed in our research, could be especially vulnerable to an increase in prejudice.

Nevertheless, it is possible that prejudice has not increased within individuals as a response to the fear of a virus. Instead, similar changes in fear of a virus and prejudice could be due to other time-independent factors, such as personality traits or third unaccounted variables. It is also possible that the pandemic provided people with an opportunity to act on their prejudice, which could be mistaken for an increase in prejudice. Consequently, distinguishing intra- from inter-individual effects would help to determine the effect of fear of COVID-19 on prejudice.

\section{Different Forms of Intergroup Contact Influence Prejudice}

Intergroup contact is a promising way to counter the potential increase in prejudice resulting from fears of the virus during a pandemic. Positive intergroup contact decreases prejudice (Paluck et al., 2018; Pettigrew \& Tropp, 2006) and negative intergroup contact increases prejudice (Barlow et al., 2012; Graf et al., 2014). While fear of COVID-19 could increase prejudice, direct positive intergroup contact could retain its reducing effect on prejudice during the pandemic and at least partially cancel out the detrimental effect of fear of COVID-19 on increasing prejudice. In line with this argument, previous research showed that past positive contact can protect against an increasing effect of negative contact on prejudice (Paolini et al., 2014). The protective role of positive contact could be theoretically extended to other factors that have an increasing effect on prejudice, including the fear of a pathogen. The protective role of

positive intergroup contact against prejudice during the COVID-19 pandemic was suggested by a study using a cross-sectional design (Alston et al., 2020). Yet, more conclusive evidence about the effect of intergroup contact on intra-individual change in prejudice during the COVID-19 is to be established. 
Problematically, the social distancing recommended as one of the ways to fight the pandemic dramatically reduced opportunities for interpersonal contact, including intergroup contact that may have already been limited prior to the pandemic (e.g., Meleady et al., 2021). Thus, intergroup contact as a tool to reduce prejudice was likely not widespread due to social distancing and similar restrictive measures imposed during the pandemic. Nevertheless, past positive contact experiences before the pandemic could still protect against an increase in prejudice that could happen due to the fear of COVID-19. In our research, we did not investigate how likely it was to experience intergroup contact during the pandemic but whether intergroup contact - experience prior to or during the pandemic - predicted changes in prejudice on an intra-individual level.

When opportunities for direct contact are missing, prejudice can be challenged by indirect forms of intergroup contact (Christ et al., 2014; White et al., 2020), such as via information about outgroups from mass media (i.e., mass-mediated contact; Graf et al., 2014; Schiappa et al., 2005). During a crisis such as a pandemic, mass media predominantly focus on a coverage of the crisis to such extent that the frequency of mass-mediated contact with outgroups is significantly reduced. However, mass-mediated intergroup contact could be intentionally employed as a more easily implementable and more widely accessible type of intergroup contact than direct contact, especially during pandemics when direct interpersonal contact is discouraged. Although the relative effect sizes of direct and mass-mediated contact were not hypothesized a priori, we have contrasted them in an exploratory fashion to inform the theory as well as potential future interventions in times where opportunities for direct contact are lacking. While positive intergroup contact is a promising strategy to reduce a potential increase in prejudice during a pandemic, negative contact could contribute to increasing prejudice, 
potentially even more than positive contact contributes to the reduction in prejudice (Barlow et al., 2019; Graf et al., 2014; Zingora et al., 2020). We investigated the effects of negative contact - both direct and mass-mediated - on prejudice to illuminate whether negative contact could exacerbate potential negative effects of the pandemic on prejudice.

\section{The Present Research}

To determine changes in anti-COVID-19 behavior and prejudice against immigrants from the Middle East during the first six months of the COVID-19 pandemic, we longitudinally tested the effect of fear of COVID-19 on both outcomes, separating intra- from inter-individual changes. Moreover, we included the effects of anti-COVID-19 norms, the impact of COVID-19 on individuals as predictors of changes in fear of COVID-19 (i.e., a mediator), anti-COVID-19 behavior, and prejudice (i.e., endogenous variables; see Figure 1 for all hypothesized relationships). Intergroup contact was further expected to predict prejudice and thus at least partially counter potential prejudice-increasing effects of other predictors. We selected immigrants from the Middle East as the target outgroup because they represent a common relevant outgroup in all countries under study. Immigration from the Middle East has been in the spotlight of public discourse across Europe in recent years. Moreover, immigrants from the Middle East are not an established but newly-arriving group in the investigated countries. This fact is suitable for testing theories rooted in the evolutionary perspective predicting that foreign groups represent a higher risk of carrying pathogens (Faulkner et al., 2004; Murray et al., 2013;

Schaller \& Park, 2011). Yet, we also employed another outgroup in the case of the Czech Republic - Vietnamese people - for the sake of a robustness check (i.e., to determine that the effect of the predictors on prejudice does not concern only migrants from the Middle East but also other groups, including established immigrant groups). 


\section{Figure 1}

Hypothesized relationships between variables.

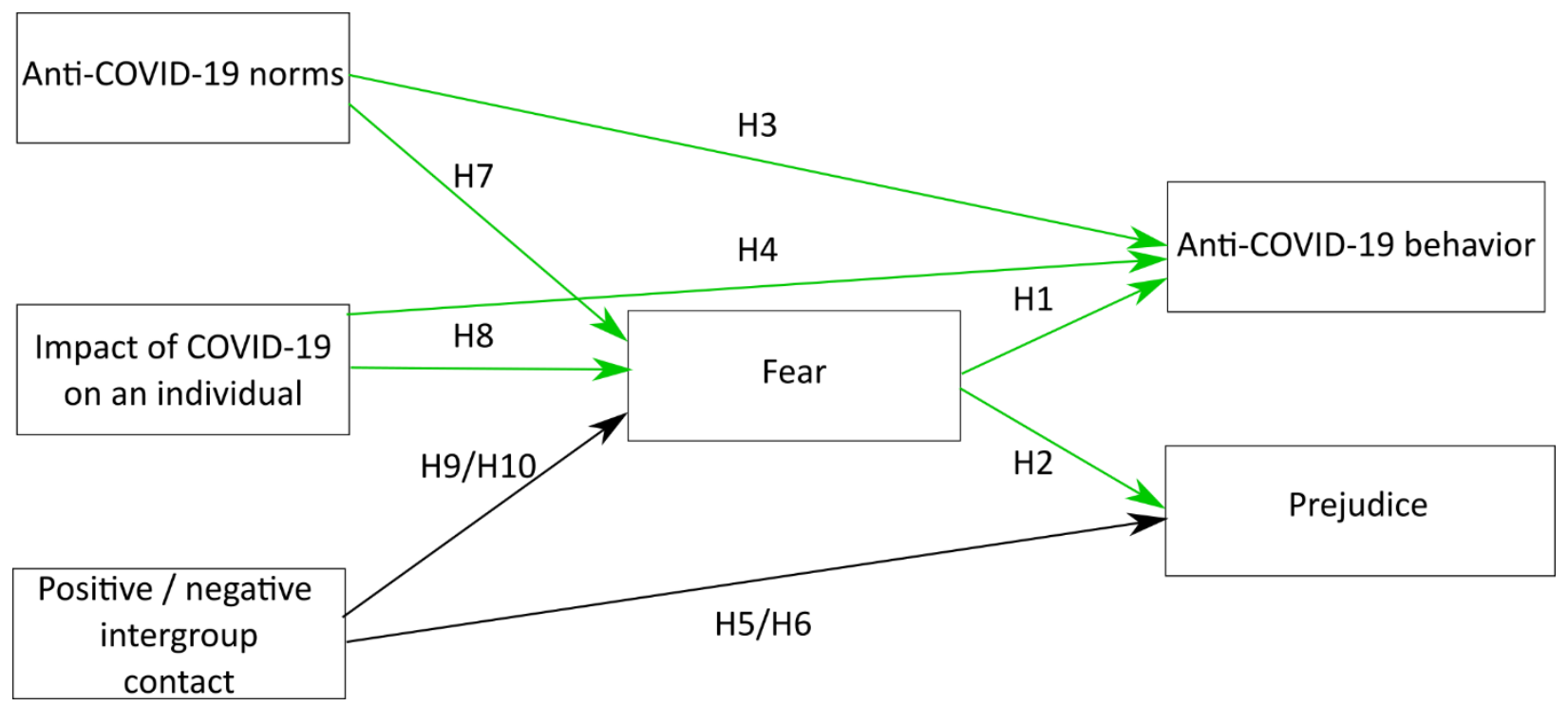

Note. Green arrows indicate positive influence. Black arrows represent the effects of positive/negative direct/mass-mediated contact, which were combined in the figure to provide a more comprehensible representation of the hypotheses. Fear represents a hypothetical joint factor of fear of COVID-19 and intergroup threat; the resulting fear factor will depend on the analysis.

To account for the potential role of social context in shaping prejudice and anti-COVID19 behavior and to obtain more robust results, we wanted to select countries that differed in terms of the COVID-19 situation (see Figure 2) as well as immigration history and where sampling was convenient. Thus, we tested our hypotheses across five European countries - the Czech Republic, Kosovo, Poland, Serbia, and Switzerland - which satisfied our criteria. With respect to the epidemiological situation in the first six months of the COVID-19 pandemic, the steepest increase in COVID-19 cases was reported in the Czech Republic and Switzerland. In contrast, the smallest increase was reported in Kosovo and Serbia. The strictest anti-COVID-19 measures were 
introduced in the Czech Republic and Poland and the most lenient measures in Switzerland. As for cross-cultural differences in migration history, Western-European countries (e.g., Switzerland) have generally hosted more foreign nationals than Central and Eastern European countries (e.g., Czech Republic, Poland). For instance, about a quarter of the Swiss population is foreign nationals, while Poland registers about $1.2 \%$ of foreign nationals with a residence permit. Moreover, Western Europeans typically report more positive attitudes towards immigrants than Eastern Europeans (Graf et al., under review; European Commission, 2018; TNS Medium Gallup, 2017).

We tested whether our proposed model applies to all countries similarly and whether the paths between variables differed between countries. We also explored whether prejudice will be less affected by predictors in countries with rich migration history (i.e., Switzerland) than in more ethnically homogenous countries (e.g., Czech Republic). More extensive experience with migration and a widespread presence of outgroups in a country, implying more opportunities for intergroup contact, can influence the link between intergroup contact and prejudice in the context of the pandemic.

\section{Figure 2}

Change in new COVID-19 cases and anti-COVID-19 restrictions across countries from April till November 2020 (the span of data sampling) 

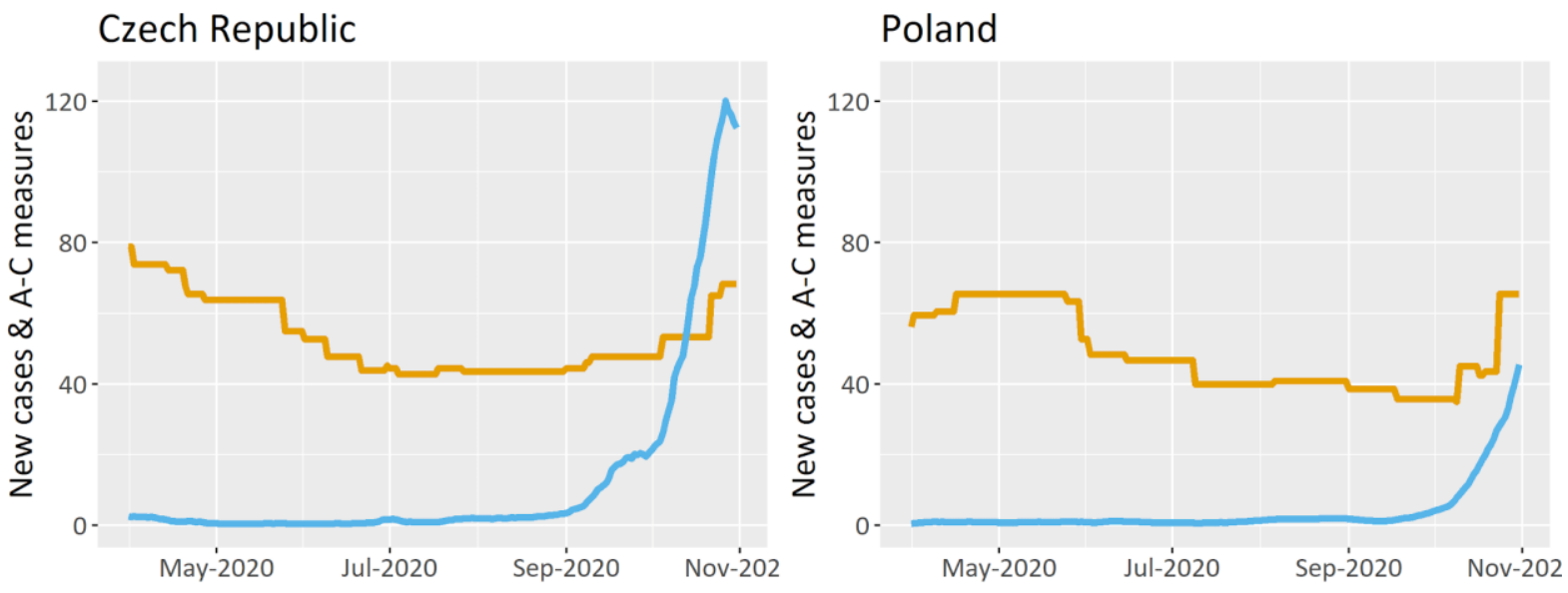

Serbia

Kosovo
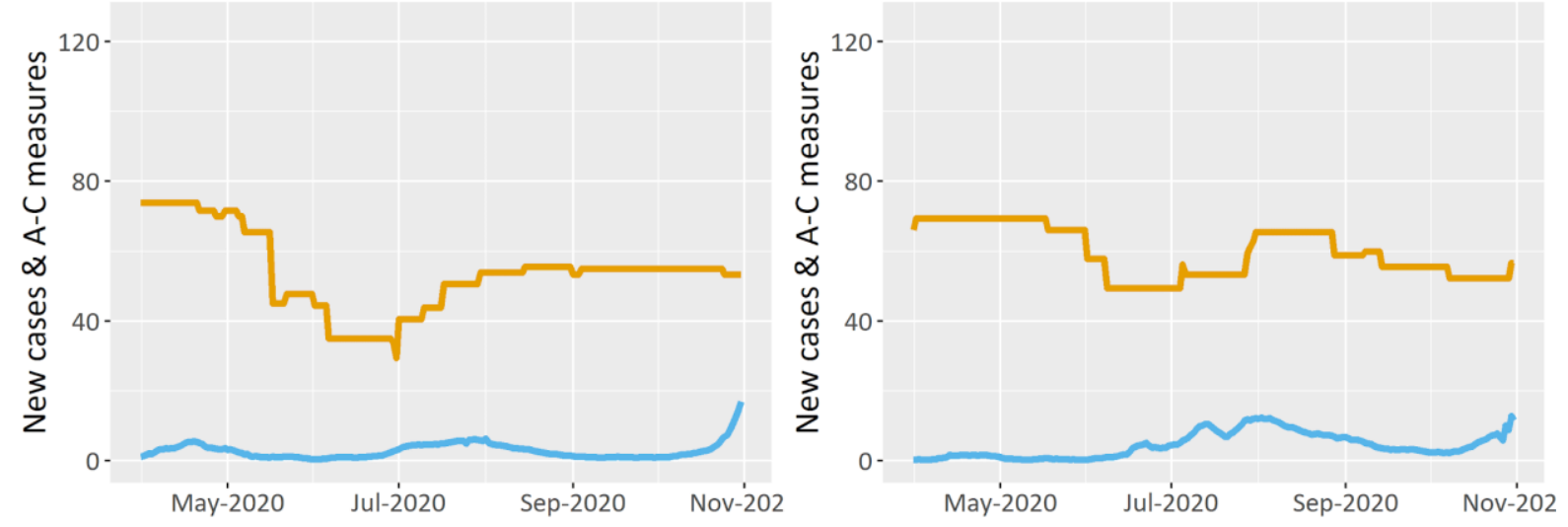

\section{Switzerland}

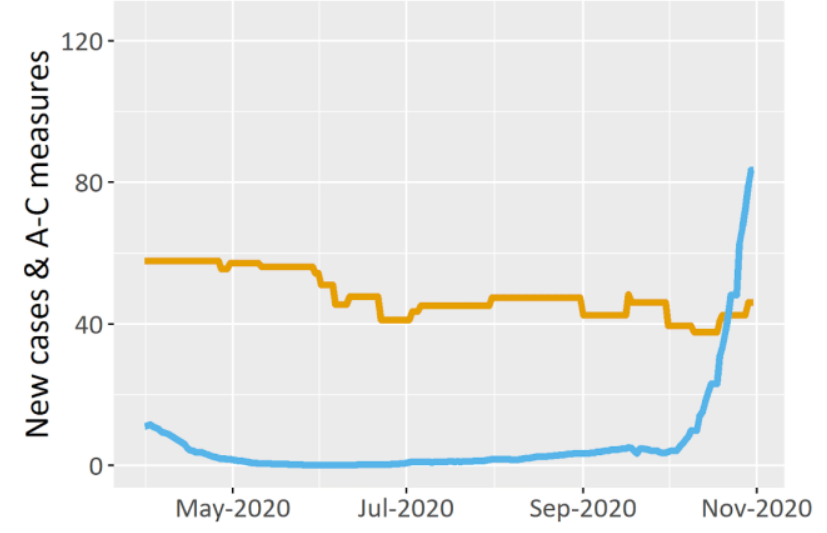

Note. New COVID-19 cases per 100000 people (New cases $=$ new cases of infected people per 100000 citizens - blue line; data source: Hasell et al., 2020) and anti-COVID-19 measures introduced by the government $(\mathrm{A}-\mathrm{C}$ restrictions $=$ the severity of restrictions introduced by the government - orange line; data source: Hale et al., 2020) are plotted on the y-axis. 
This study aims to extend the current knowledge of factors that influence prejudice and behaviors aimed at reducing virus transmissions in the context of a pandemic. From a theoretical perspective, we combined premises of the Fear-Appeal Theory and theories predicting an increase in prejudice as a consequence of being afraid of a pathogen, such as the Behavioral Immune System model (Schaller \& Park, 2011; Witte \& Allen, 2000), to hypothesize a mutual increase in anti-COVID-19 behavior and prejudice due to a common predictor - fear of COVID19. Drawing on health-oriented behavior and intergroup literature, we identified two factors that could affect fear of COVID-19 - anti-COVID-19 norms as well as an impact of COVID-19 on individuals - and, in turn, anti-COVID-19 behavior as well as prejudice. Furthermore, we employed intergroup contact theory in investigating protective factors that could at least partially level out the hypothesized increasing effect of fear of COVID-19 on prejudice.

In summary, the contribution of the present research is a rich cross-pollination of various theoretical accounts that address distinct but related aspects of social reality amidst the unprecedented situation of a global pandemic. Unlike past research, the methodological and analytical approach employed in the present study (i.e., longitudinal design across countries, distinguishing between intra- and inter-individual change) promises currently missing highquality evidence that represents an adequate test of the hypotheses derived from a multi-faceted theoretical background.

\section{Method}

\section{Procedure}

Our initial preregistered plan was to collect two-waves of longitudinal data from at least 300 participants in the Czech Republic, Kosovo, Poland, Serbia, Switzerland, and the United Kingdom. Based on the changing and ongoing pandemic situation, we also decided to collect a 
third wave of data. Using three-waves instead of two-waves of data enabled us to capture more reliable and complex relationships between variables in the context of the pandemic, since we could determine developmental trends in participants (Hamaker et al., 2015). Details on the sample size justification can be found in the Online Supplemental Materials (OSM). The United Kingdom sample was not included in the analysis because we were not able to sample the third wave in the UK due to financial limits. In the OSM, we present findings of a cross-lagged panel model that included two waves from all six countries. The invariance test showed that the UK did not differ from the other five countries, indicating that its exclusion did not alter the results. All analyses were conducted after the third wave was collected in all countries.

The completion of the survey took approximately 30 minutes and was administered via the formr survey framework (Arslan et al., 2020). The first data collection was conducted in the second half of May 2020, the second data collection in the second half of June 2020, and the third data collection in mid-October 2020. Czech participants were contacted via an already existing research participant pool, Polish and Serbian participants were contacted via social networks (e.g., Facebook), Kosovo and Swiss participants were contacted through university mailing lists, UK participants were contacted via the participant-recruiting service Prolific. All participants were included in a financial draw, except for participants in the UK who were paid for the completion of the survey.

The research was preregistered on the Open Science Framework (see https://osf.io/kszx2/?view_only=1c53728255124d839f92d001999ecc46). The questionnaire, analysis code, and data are publicly available (see https://osf.io/p7kg8/?view_only=9ff598325df741efb40181c61404a20a). Deviations from the preregistration, including new analytical steps, are listed in Tables A1 and A2 in OSM. 
The study was approved by the Ethics board of the Institute of Psychology, Academy of Sciences of the Czech Republic (Ref. no.: PSU-503/Brno/2020) and the Ethics committee of the Faculty of Human Sciences, University of Bern. The study was evaluated as a minimum-risk procedure, finding it compliant with the guidelines for human subject research in the Czech Republic and the EU. The English version of the questionnaire was translated into other language versions; back-translation ensured that the translation into different languages did not compromise the findings.

\section{Participants}

In the final sample, participants with less than $80 \%$ of missing values and those who completed the survey in the first wave were included, resulting in 3899 participants (NT2 = 1793, NT3 = 1660) without UK participants. Descriptive statistics of participants are shown in Table D1 in the OSM. In line with the preregistration, we collected data from at least 300 respondents in each country.

\section{Measures}

The description of items and variables is presented in Table 1. The full questionnaire is available online (https://osf.io/p7kg8/?view_only=2429c033be704f339bae7f02bf787a01). The endogenous variables - fear of COVID-19, anti-COVID-19 behavior, and prejudice-were treated as latent variables. The exogenous variables - anti-COVID-19 norms, the impact of COVID-19, and intergroup contact—were treated as manifest variables. Factor analysis supported the expected construct structure. Control variables included education, income, age, gender, and minority background. Before the main analysis, we constructed scales using exploratory and multi-group confirmatory factor analysis (for more details see the OSM). AntiCOVID-19 behavior was estimated using four indicators capturing important aspects of behavior 
that should limit the transmission of the virus during the pandemic - support for governmental restrictions, social distancing, following other recommendations such as washing hands more frequently since the outbreak of the pandemic, and wearing protective clothing such as facemasks and gloves. Prejudice was indicated by distancing from an outgroup, intergroup threat, and intergroup bias, which are often used as indicators of prejudice. Further, prejudice also comprised support for policies such as a) preferential treatment of ingroup members in hospitals during the pandemic, b) a restricted entry to a country for migrants from the Middle East, and c) the restriction of spending resources by a government to help migrants from the Middle East. Fear of COVID-19 was estimated by four indicators - fear of getting infected, fear of being economically affected, fear that one's loved ones and the country will be adversely affected by the pandemic.

We also inspected whether fear of COVID-19 and intergroup threat create a common factor called fear of the unknown. The analysis revealed that this was not the case, instead, intergroup threat was an indicator of prejudice (for more details on scale construction please see the OSM).

Table 1

Variable Description

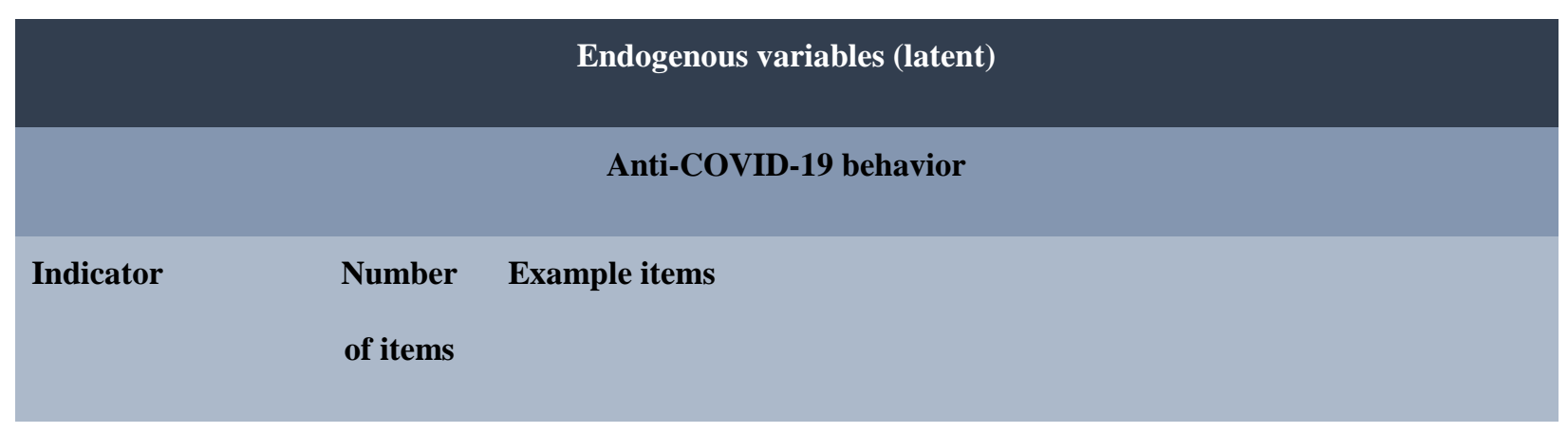




\begin{tabular}{|c|c|c|}
\hline Supporting & 4 & To what extent do you support the following measures that should stop the \\
\hline governmental & & spread of COVID-19? \\
\hline restrictions & & Closing borders \\
\hline Social distancing & 3 & $\begin{array}{l}\text { Estimate how many times you have gone out to engage in activities that } \\
\text { involved people from outside of your household (e.g., going for a walk) in the } \\
\text { last } 5 \text { days. }\end{array}$ \\
\hline $\begin{array}{l}\text { Following other } \\
\text { recommendations }\end{array}$ & 3 & I wash my hands more intensely than before the spread of COVID-19. \\
\hline $\begin{array}{l}\text { Wearing protective } \\
\text { clothing }\end{array}$ & 2 & I cover my mouth in public places (e.g., shops, workplace). \\
\hline \multicolumn{3}{|r|}{ Prejudice } \\
\hline Indicator & $\begin{array}{l}\text { Number } \\
\text { of items }\end{array}$ & Example items \\
\hline Social distance & 4 & Would you mind if a migrant from the Middle East becomes your neighbor? \\
\hline Support for policies & 3 & $\begin{array}{l}\text { If medical equipment and care get scarce during the COVID-19 pandemic, } \\
\text { [country] people should get preferential treatment in hospitals over migrants } \\
\text { from the Middle East. }\end{array}$ \\
\hline Intergroup threat & 4 & $\begin{array}{l}\text { Migrants from the Middle East in the [country] would endanger the safety of } \\
\text { [national] people. }\end{array}$ \\
\hline Ingroup bias & 1 & $\begin{array}{l}\text { Score on feeling thermometer towards immigrants subtracted from feeling } \\
\text { thermometer towards ingroup. }\end{array}$ \\
\hline & & Fear of COVID-19 \\
\hline
\end{tabular}




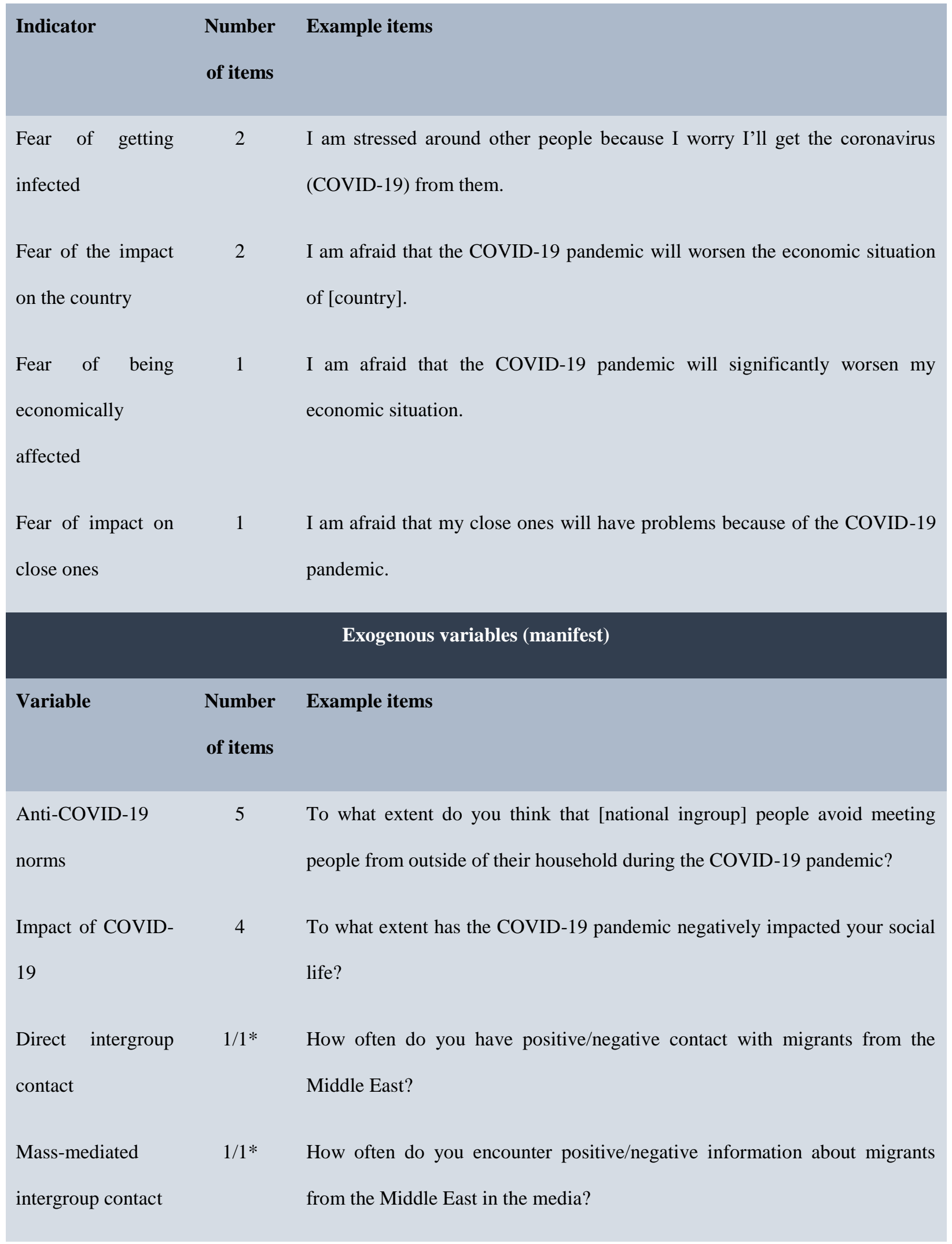


Note. $*=$ both direct and mass-mediated intergroup contact included positive and negative contact, which were treated separately in the analysis. We used four intergroup contact variables in totalpositive and negative direct contact; positive and negative mass-mediated contact.

\section{Analytical Approach}

We analyzed the three-waves of data using a latent change score model (LCSM), which enabled us to capture various types of temporal links between variables (Hounkpatin et al., 2018; Kievit et al., 2018; Klopack \& Wickrama, 2020). In LCSM, intra-individual effects refer to prospective temporal relations between variables, thus, one variable predicts latent change score in a second variable within an individual, after accounting for inter-individual variance in growth patterns. This means that the LCSM can also estimate and control for inter-individual differences - latent growth patterns or mean-level change - which are random effects allowed to vary across individuals.

The investigation of intra- and inter-individual factors helps identify whether two variables are related in time or whether different factors can be responsible for their similar developmental trajectories, which improves (but does not enable) causal inferences (Kievit et al., 2018; Klopack \& Wickrama, 2020). A relationship between two inter-individual factors means that two variables change in a similar manner over time, however, this does not mean that one variable precedes the other in time. If trajectories of two variables are related, but intraindividual effects are missing, this implies a confounding effect of a third unobserved factor (Hounkpatin et al., 2018). Furthermore, the LCSM allows the investigation of initial levels in variables (i.e., intercepts at T1). It is possible that initial levels of two variables are related, which could be used as tentative evidence for one affecting another in cross-sectional studies. However, developmental trajectories and prospective changes might not be related, implying that 
temporal relations between variables do not exist. In our research, we estimated changes in endogenous variables - fear of COVID-19, anti-COVID-19 behavior, and prejudice. We tested whether exogenous variables at Time $\mathrm{X}$ - anti-COVID-19 norms, the impact of COVID-19, and intergroup contact - predicted changes in endogenous variables that occurred between Time X-1 and Time X (X to be substituted either for 2 or 3). Such effects represent exogenous shocks (i.e., effects of exogenous variables on changes in endogenous variables after taking into account the general growth pattern). In the model, we included effects of endogenous variables on exogenous variables at a subsequent wave, however, these effects are not described in this article because they were not related to our hypotheses.

We first determined measurement invariance (see Table 2) by sequentially constraining parameters over time and countries. If the model fit is not significantly worsened by introducing new restrictions on parameters, a more parsimonious model is preferred because it improves the interpretation of the results (Ferrer et al., 2008; Vandenberg \& Lance, 2000). Step-by-step, configural equivalence is contrasted with metric invariance and metric invariance with scalar invariance. We focused on invariance across time, which was necessary for investigating the change in constructs. In the case of countries, we focused on the equality of regression paths, which indicates whether relationships between variables differed among countries.

All variables were scaled before they were analyzed. We included control variables into each model (i.e., age, gender, education, income, and belonging to an ethnic, sexual, or religious minority). We used Full-Information Maximum likelihood (FIML) to handle missing values. Standardized coefficients from the final model were bootstrapped using 1500 samples. We report bootstrapped point estimates of regression coefficients, standard errors, and 95\% confidence intervals. 
The statistical analyses were performed in $R$ (v4.0.3), using the following packages lavaan (v0.6-7; Rosseel, 2012) and sjstats (v0.18; Lüdecke, 2020).

\section{Table 2}

Contrasting Models to Establish Measurement Invariance

\begin{tabular}{lccc}
\hline Level & RMSEA [90\% CI $]$ & SRMR & CFI \\
\hline Configural & $.037[.035, .038]$ & .079 & .936 \\
Metric-time & $.037[.035, .038]$ & .079 & .935 \\
(excluding manifest variables) & & & \\
Metric-time & $.035[.034, .036]$ & .076 & .912 \\
(including manifest variables) & $.037[.036, .038]$ & .078 & .903 \\
Partial-scalar-time & $.038[.037, .039]$ & .076 & .890 \\
Partial-scalar-time \& metric-country \& paths & & & \\
restricted across countries & & $.040[.039, .041]$ & .082 \\
Partial-scalar-time \& metric-country \& paths & & & \\
restricted across countries \& controls & & & \\
\end{tabular}

Note. The configural model did not include manifest variables. Thus, we provide fit indices for configural and metric-time-invariant models that do not contain manifest variables to compare two models containing only different equality restrictions. The following models included manifest variables. Models should be compared as follows: 1. Configural vs. metric-time (excluding manifest variables); 2. Metric-time (including manifest variables) vs. partial-scalar-time; 3. Partialscalar-time vs. partial-scalar-time \& metric-country; 4. Partial-scalar-time \& metric-country vs. partial-scalar-time \& metric-country \& controls. Criteria used to compare model fits (Chen, 2007): 
models are considered to yield the same model fit if adding equality constraints does not worsen CFI for .01 and simultaneously RMSEA for .015, and change in SRMR for .03. Due to the high complexity of our model, values slightly higher than these thresholds are considered to support measurement invariance.

\section{Results}

\section{Measurement invariance}

We established partial scalar time-invariance in the case of fear of COVID-19 and antiCOVID-19 behavior and full scalar time-invariance in the case of prejudice. When it comes to differences between countries, we were interested only in metric invariance to establish that indicators referred to the same construct. Regression paths were equaled between countries, and the likelihood ratio test confirmed that the paths did not differ between countries. This also indicates that differences in sampling strategies did not result in an exaggeration of differences in path coefficients across countries. Although a chi-square difference was significant, $\Delta \chi^{2}=308.5$, $\Delta \mathrm{df}=156, p<.001$, information criteria AIC and BIC, AIC: 239742 vs. 239738 , BIC: 247862 vs. 246887, as well as comparison in CFI, RMSEA, and SRMR gave preference to a model containing restricted paths across countries. This illustrates no differences in effect sizes between countries, thus, prejudice was affected by predictors to a similar extent regardless of the migration history of the country. The configural model did not converge when manifest variables were included; however, this was expected since the LCSM model is highly complex (Kievit et al., 2018). Therefore, we contrasted the configural model with a time-metric-invariant model that did not include the manifest variables. The next comparisons were based on models that contained the manifest variables. In the final model, we included control variables and regressed them with all other variables. Although the inclusion of controls worsened the model fit, it did 
not have any effect on the interpreted effects (i.e., the model with and without controls did not differ).

\section{Intra-individual effects: Test of the hypotheses}

Hypothesis testing was based on intra-individual effects. In Table 3, we present all intraindividual effects concerning endogenous variables. We also indicate whether significant effects were hypothesized (i.e., preregistered) or non-hypothesized to ease interpretation. Hypothesized effects are generally considered more reliable than non-hypothesized significant effects. Intraindividual effects are also graphically presented in Figure 3.

\section{Effect of fear of COVID-19 on outcomes}

Fear of COVID-19 and anti-COVID-19 behavior were associated on an intra-individual level, however, disentangling the temporal precedence showed that anti-COVID-19 behavior increased fear of COVID-19 but fear of COVID-19 did not influence anti-COVID-19 behavior, thus rejecting H1. This means that fear of COVID-19 did not motivate anti-COVID-19 behavior, but people more frequently performing anti-COVID-19 behavior felt greater fear of COVID-19. Moreover, the general changes in fear of COVID-19 and in anti-COVID-19 behavior were related, suggesting that a confounding factor, such as a third unobserved factor, was responsible for their similar change beyond the intra-individual influence of anti-COVID-19 behavior on fear of COVID-19.

Fear of COVID-19 did not predict prejudice on an intra-individual level, rejecting H2. Initial levels of fear of COVID-19 and prejudice were significantly related but their trajectories on the inter-individual level differed. Thus, the higher the initial fear of COVID-19, the more likely respondents reported higher prejudice. Otherwise, changes in fear of COVID-19 and prejudice were unrelated, suggesting no temporal relationship. 


\section{Exogenous predictors of outcomes}

In line with H3, anti-COVID-19 behavior was facilitated by anti-COVID-19 norms. The impact of COVID-19 on individuals' lives did not affect anti-COVID-19 behavior, thus not supporting H4. Unexpectedly, negative direct and negative mass-mediated contact with immigrants from the Middle East predicted an increase in anti-COVID-19 behavior but the effects were small. Prejudice negatively predicted anti-COVID-19 behavior on an intraindividual level, thus, the higher the prejudice, the more likely a decrease in anti-COVID-19 behavior.

H5 and H6 were supported in that positive direct and negative direct contact affected intra-individual change in prejudice. Similarly and in line with H5 and H6, positive and negative mass-mediated contact predicted an intra-individual change in prejudice. The direction of the effect depended on the valence of intergroup contact; positive contact decreased, while negative contact increased prejudice. However, the effects of intergroup contact on prejudice were small. We exploratively contrasted the effects of direct and mass-mediated contact by comparing model fits of the model in which effects of direct and mass-mediated contact were freely estimated and the model in which effects of direct and mass-mediated contact were constrained to be equal. In both models, effects of intergroup contact on prejudice were estimated separately within each country. We conducted two comparisons separately for positive and negative contact. We did not find a significant difference between the effects of direct and mass-mediated contact (positive contact: $\Delta \chi 2=8.26, \Delta \mathrm{df}=5, \mathrm{p}=.142$; negative contact: $\Delta \chi 2=4.49, \Delta \mathrm{df}=5, \mathrm{p}=.481)$. Unexpectedly, anti-COVID-19 norms predicted an increase in prejudice, meaning that participants' perception that others engage in behaviors limiting the virus transmission increased 
participants' prejudice against migrants from the Middle East. Anti-COVID-19 behavior did not predict prejudice.

In line with H8, fear of COVID-19 was increased by the impact of COVID-19 but, in contrast to H7, fear of COVID-19 was unaffected by anti-COVID-19 norms. Unexpectedly, positive direct and negative mass-mediated contact were positively related to the change in fear of COVID-19. However, these effects were small.

\section{Table 3}

Intra-Individual Effects

\begin{tabular}{lllll}
\hline Endogenous variable & Exogenous variable & Point estimate $\beta$ & $95 \%$ CI & SE
\end{tabular}

\section{Anti-COVID-19 behavior}

Hypothesized effects

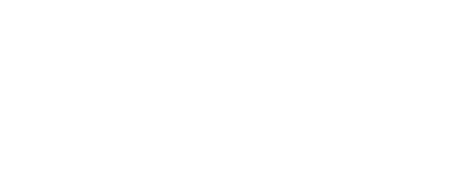

Non-hypothesized effects

Prejudice

Positive direct contact

Negative direct contact

Positive mass-media

contact

Negative mass-media $.085^{*}$

.137

$-.032$

$.092^{*}$

.043
.164

$-.184, .458$

$.160, .333$

.044

$$
.246^{* * *}
$$

$-.143, .097$

.061

$-.242^{* *}$

$-.415,-.069$

.088

$-.105, .041$

.037

$.012, .172$

.041

$-.026, .113 \quad .035$

contact 


\section{Prejudice}

Hypothesized effects

Hypothesized effects

Non-hypothesized effects
Fear of COVID-19

Negative direct contact

Positive mass-media

contact

Negative mass-media

contact

Anti-COVID-19

behavior

Anti-COVID-19 norms

Impact of COVID-19

$-.058 \quad-.316, .200$

$\begin{array}{lll}-.064^{*} & -.123,-.004 & .030\end{array}$

$\begin{array}{lll}.133^{* * *} & .067, .199 & .034\end{array}$

$-.077^{*}$

$-.143,-.011 \quad .034$

$.121^{* *}$

$.038, .204$

.042

$-.009$

$-.274, .256$

.135

$.252^{* * * *}$

$.152, .352$

.051

$-.053$

$-.167, .061$

.058

\section{Fear of COVID-19}

Hypothesized effects

Non-hypothesized effects
Anti-COVID-19 norms

Impact of COVID-19

Anti-COVID-19

behavior

Prejudice

Positive direct contact

Negative direct contact
.024

$.448^{* * * *}$

$.421^{\text {***** }}$

.017

$.059^{*}$

$-.025$
$.201, .641$

.112

$-.078, .112$

$.011, .108$

.025

$-.035, .083 \quad .030$

$.358, .537 \quad .046$

$-.077, .026 \quad .026$ 


\section{contact}

Negative mass-media

contact

${ }^{*} p<.05,{ }^{* *} p<.01,{ }^{* * *} p<.001$.

Note. Significant effects are bold.

\section{Figure 3}

Latent change score model 


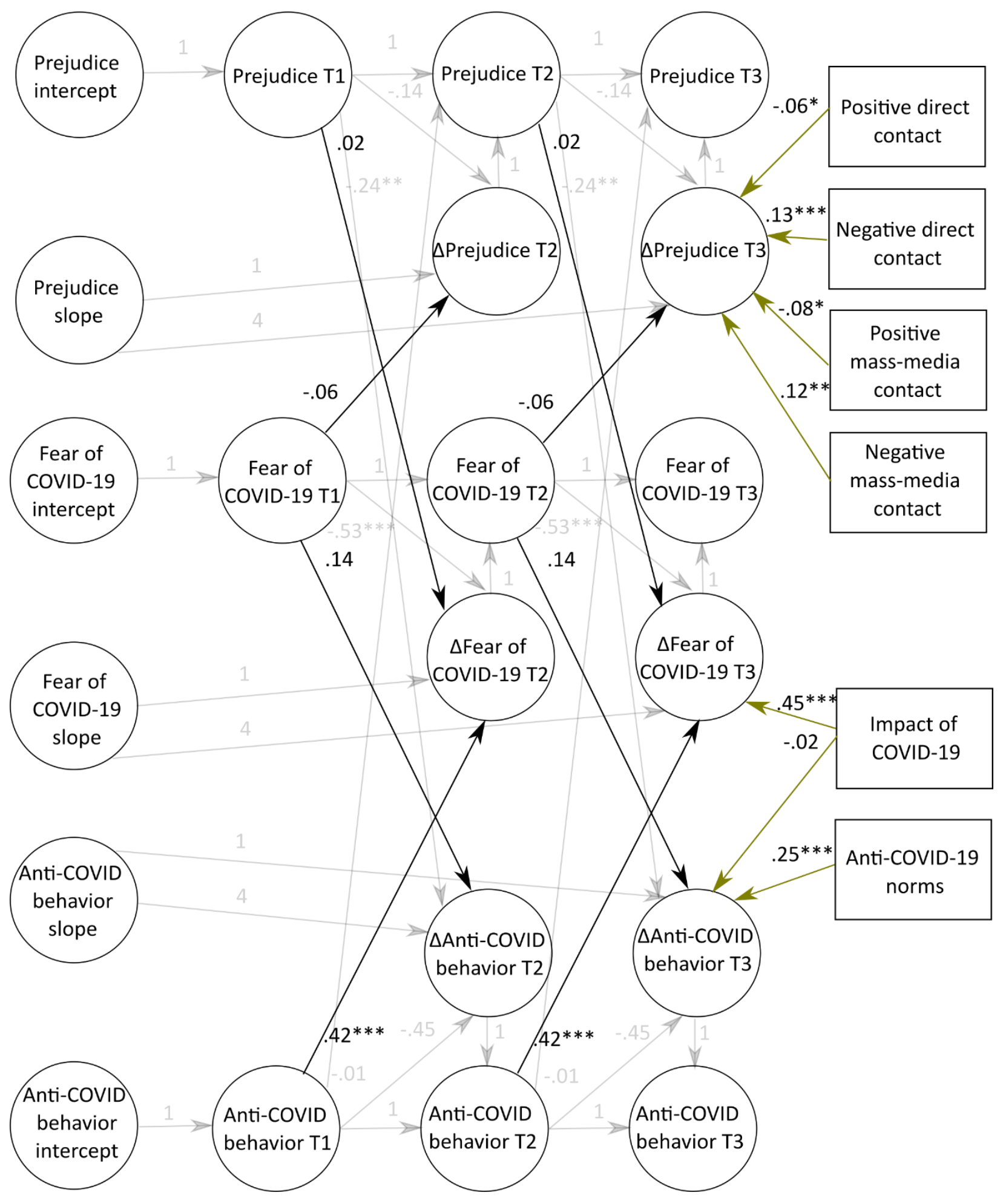

Note. Changes in fear of COVID-19, anti-COVID-19 behavior, and prejudice are modeled. We report all modeled links between endogenous variables. For the sake of clarity, hypothesized effects are highlighted in black, and other estimates are grey. All coupling effects between 
endogenous variables are also black because the model allows for testing temporal precedence, except for the links between anti-COVID-19 behavior and prejudice because their relationship was not hypothesized. In the case of exogenous variables, we only report their effects on latent change scores (i.e., intra-individual changes in endogenous variables); these effects are highlighted with green arrows. The effects of exogenous variables on endogenous variables were estimated twicean effect of exogenous variables measured at $\mathrm{T} 1 / \mathrm{T} 2$ on endogenous variables estimated at $\mathrm{T} 2 / \mathrm{T} 3-$ and averaged because it did not worsen model fit.

\section{Inter-individual effects}

Inter-individual factors included slopes (i.e., latent growth trajectories) and intercepts (i.e., initial levels) of fear of COVID-19, anti-COVID-19 behavior, and prejudice. We did not test our hypotheses using inter-individual effects, however, they provide more detailed insights into relations between endogenous variables.

A mean change in fear of COVID-19 copied the increase in new COVID-19 cases in countries (see Figure 2). In the country with the highest increase in COVID-19 cases, the Czech Republic, fear of COVID-19 had a tendency to increase during the early six months of the COVID-19 pandemic, $e s t=1.32,95 \%$ CI $[.89,1.76], S E=.22$. In the country with about half of the increase in COVID-19 cases in comparison to the Czech Republic, Switzerland, fear of COVID-19 did not change, $e s t=-.26,[-1.13, .61], S E=.44$. In countries with the smallest increase in COVID-19 cases-Kosovo, Poland, Serbia-fear of COVID-19 had a tendency to decrease, Kosovo: $e s t=-.76,[-1.50,-.02], S E=.38$, Poland: $e s t=-1.34,[-2.09,-0.59], S E=.38$, Serbia: $e s t=-1.19,[-1.64,-.74], S E=.23$,

Intercepts and slopes of endogenous variables were not associated with each other, which means that the mean change of endogenous variables did not depend on the initial level of any 
endogenous variable. For instance, the general change in anti-COVID-19 behavior was not influenced by initial levels of anti-COVID-19 behavior, fear of COVID-19, or prejudice, thus, anti-COVID-19 behavior changed similarly across respondents regardless of their initial levels of anti-COVID-19 behavior, fear of COVID-19, or prejudice. We found three noticeable associations between inter-individual variables. Intercepts of fear of COVID-19 and antiCOVID-19 behavior were associated with each other, which means that the higher the fear of COVID-19 at T1, the higher the anti-COVID-19 behavior at T1. Slopes of fear of COVID-19 and anti-COVID-19 behavior were also associated with each other, which means that both variables changed in the same direction, indicating that a third unobserved factor beyond those included in the model could be responsible for their similar change. Intercept and slope of antiCOVID-19 behavior were negatively associated, which indicates that anti-COVID-19 behavior was more likely to decrease among participants who reported more frequent anti-COVID behavior at T1. Associations between slopes and intercepts of endogenous variables are presented in Figure 4; green represents a positive association, red a negative association; the darker the color, the stronger the association between factors.

\section{Figure 4}

Correlations between slopes and intercepts of endogenous variables - fear of COVID-19, antiCOVID-19 behavior, and prejudice 
(1)

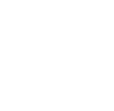

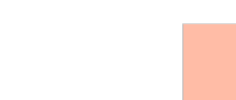

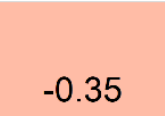

I Fear COVID-19-

$$
1
$$

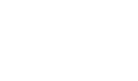

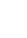

\begin{tabular}{|c|c|c|c|}
\hline & -0.35 & 0.07 & -0.07 \\
\hline-0.26 & 0.46 & 0.14 & 0.13 \\
\hline
\end{tabular}

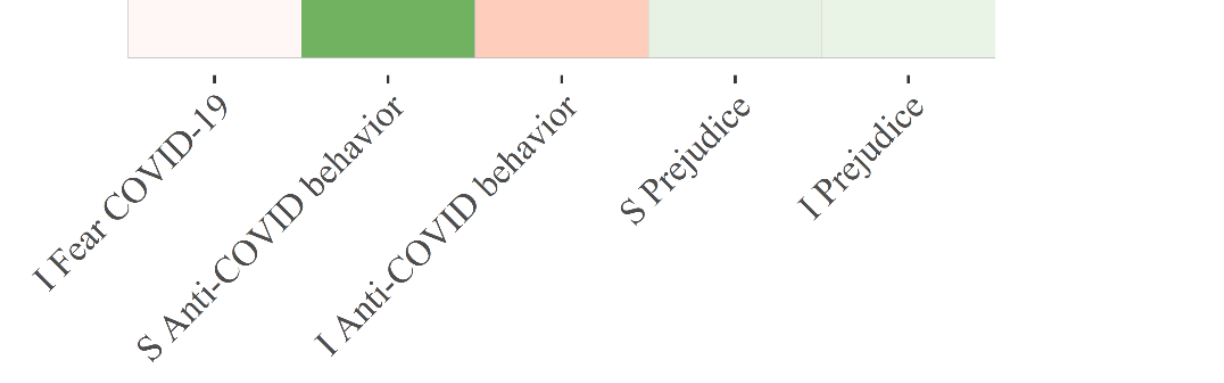

Note. $\mathrm{I}=$ intercept, $\mathrm{S}=$ slope.

\section{Robustness Check: Prejudice}

Prejudice against one outgroup is more likely to generalize to another outgroup if outgroups are perceived as similar (Harwood et al., 2011). Because the outbreak of the pandemic was linked to China, prejudice against groups that are perceived as similar to Chinese people could have been affected more than prejudice against dissimilar groups. Furthermore, prejudice may have increased most significantly at the start of the pandemic when people were first confronted with the virus. Therefore, in a robustness check, we accounted for two potential issues related to the change in prejudice in the context of the pandemic: We examined 1) prejudice against an outgroup that is viewed as more similar to the Chinese than the immigrants 
from the Middle East, Vietnamese people; and 2) change in prejudice prior to the outbreak of the pandemic. This robustness check was conducted only in the Czech Republic due to the availability of data before the pandemic from an existing research participant pool. We focused on Vietnamese people, as they are one of the largest ethnic minorities in the otherwise very homogenous Czech Republic, where other Asian minorities are much rarer. Moreover, thanks to data availability, we could investigate individual changes in prejudice against Vietnamese people that occurred before and after the onset of the pandemic.

This robustness check supported our findings; the results of models that contained either prejudice against Vietnamese people or immigrants from the Middle East resembled each other (for more details about this robustness check please see the OSM).

Previous research on terror management theory suggested that mortality salience increases prejudice only among individuals with certain characteristics, such as right-wing authoritarianism (Weise et al., 2012). Thus, we included political orientation, which is related to RWA as a control variable in another robustness check. The results did not significantly change when including and excluding political affiliation as a covariate from the analysis.

Finally, the indicator of prejudice "support for policies aimed at migrants from the Middle East" could be specific for the COVID-19 pandemic situation at a given time and obscure the results. A performed robustness check showed that dropping this indicator from the main model did not influence the results.

\section{Discussion}

In a three-wave longitudinal study spanning six months at the beginning of the COVID19 pandemic across five European countries, we investigated whether: 1) fear of COVID-19 increased both anti-COVID-19 behavior and prejudice; 2) anti-COVID-19 norms and the impact 
of the COVID-19 pandemic on an individual influenced anti-COVID-19 behavior and prejudice either directly or indirectly through fear of COVID-19; 3) intergroup contact affected prejudice in the course of the pandemic. We tested our hypotheses using intra-individual effects (i.e., what affects changes within single participants) while controlling for inter-individual effects (i.e., mean-level changes between participants and initial levels of outcomes).

Fear of COVID-19 did not predict an increase in anti-COVID-19 behavior or prejudice on an intra-individual level, rejecting $\mathrm{H} 1$ and $\mathrm{H} 2$. In other words, while we did not find support for the notion that fear of COVID-19 increased prejudice, fear of COVID-19 did not increase anti-COVID-19 behavior either. This finding addresses theories that postulate an important role of fear of a virus in shaping prejudice and behavior that should reduce the virus transmission. Specifically, we found no support for fear-appeal theories suggesting that inducing fear of COVID-19 within individuals should stimulate their anti-COVID-19 behavior (Witte \& Allen, 2000). We also did not find support for theories predicting that virus-related threat leads to a rise in prejudice, such as the Behavioral Immune System model (Schaller \& Park, 2011).

Consequently, fear of COVID-19 could not function as a factor mediating the influence of other predictors, and was not directly related to anti-COVID-19 behavior or prejudice. In this study, we uniquely combined health-related and intergroup literature to show that fear of COVID-19 did not affect anti-COVID-19 behavior and prejudice, due to the missing link from fear of COVID-19 to anti-COVID-19 behavior or prejudice within individuals. These findings have farreaching consequences for re-evaluation of existing theories (often based on less methodologically-refined evidence) that predict intra-individual effects of fear of COVID-19 on both anti-COVID-19 and prejudice. 
In contrast, we found evidence that COVID-19 norms stimulated anti-COVID-19 behavior, supporting H3. This finding enriches our understanding of how people navigate their behavior during pandemics. Our results indicate that social norms, rather than fear, should be the focus of strategies aiming to induce behavior that limits virus transmission during pandemics. In the case of prejudice, positive intergroup contact predicted its decrease, while negative contact had an increasing effect, supporting H5 and H6. This evidence complements intergroup contact research searching for an answer to whether intergroup contact influences prejudice even in the context of the COVID-19 pandemic, in cases where longitudinal data were not employed or intra-individual changes were not tested (e.g., Alston et al., 2020).

\section{Change in Anti-COVID-19 Behavior}

Fear of COVID-19 did not predict change in anti-COVID-19 behavior on an intraindividual level. This finding supports the notion that fear of disease alone may not be sufficient to induce health-related behavior. A potential reason for why fear of COVID-19 did not promote anti-COVID-19 behavior could be a lack of self-efficacy (Kok et al., 2018). During a pandemic, a collective effort is needed to fight the spread of a virus. Consequently, people may feel no control over getting infected or over avoiding the negative effects of the pandemic. In a similar vein, the importance of communication styles when inducing support for anti-COVID behavior was demonstrated in a cross-national experiment, whereby an autonomy-supportive communication style was more effective than a controlling style (Legate, 2022). The autonomysupportive communication style was characterized by endorsing perspective-taking, providing meaningful rationale, and supporting individual agency. Theoretically, inducing such autonomy in conjunction with fear of COVID-19 could result in an increase in observing anti-COVID-19 behavior. Alternatively, it may be more efficient to induce self-efficacy rather than fear of a virus 
to increase behavior that should limit virus transmission in the context of a pandemic (Jørgensen et al., 2021). Future research could investigate whether self-efficacy is an important barrier for stimulating behavior that should limit virus transmission in the context of a pandemic.

Despite fear of COVID-19 not predicting change in anti-COVID-19 behavior on an intraindividual level, fear of COVID-19 was associated with anti-COVID-19 behavior on an interindividual level. Specifically, mean-level changes and initial levels of fear of COVID-19 and anti-COVID-19 behavior were associated beyond their intra-individual relationship, indicating a confounding effect of a potential third unobserved factor that could affect both of them. Critically, this finding could have been previously mistaken for the influence of fear of COVID19 on anti-COVID-19 behavior reported by cross-sectional studies or potentially even in longitudinal studies where intra- and inter-level changes were not distinguished (Hounkpatin et al., 2018). Moreover, anti-COVID-19 behavior increased fear of COVID-19, highlighting the importance of determining temporal precedence. The effect of anti-COVID-19 behavior on fear of COVID-19 could be explained in light of research on cognitive dissonance, whereby people seek justification for their actions (Harmon-Jones \& Mills, 2019). Nevertheless, it is possible that a certain level of fear of COVID-19 was necessary at the beginning of the COVID-19 pandemic for people to willingly perform anti-COVID-19 behaviors; the determined, strong link between the initial levels of these two variables in our research may suggest such a tendency.

Of all the predictors, anti-COVID-19 norms were the only factor that shaped antiCOVID-19 behavior on the intra-individual level, meaning that it was the behaviors of others observed in one's social environment that influenced participants' behavior. This finding applied even after controlling for a general change in anti-COVID-19 behavior among participants. The determined effect of anti-COVID-19 norms on anti-COVID-19 behavior supports the argument 
that norms are crucial for guiding relevant behaviors, especially in the presence of danger such as the COVID-19 pandemic (Fritsche et al., 2011; Giannakakis \& Fritsche, 2011; Jonas et al., 2008), corroborating theories such as the social identity theory (Terry \& Hogg, 1996).

The other predictor, the impact of COVID-19 on participants, was unrelated to an intraindividual change in anti-COVID-19 behavior. This does not support our expectation that the more participants or their close ones were affected by the pandemic, the more likely they were to behave in line with guidelines aimed to flatten the COVID-19 incidence curve in the population. The reason for this may be that being significantly affected by the governmental restrictions could result in fatigue or low support for anti-COVID-19 behavior which would extend the impact of the pandemic on the personal situation even further (Petherick et al., 2021). Consequently, the impact of the pandemic could be unrelated to the anti-COVID-19 behavior. However, the individual impact of the pandemic increased fear of COVID-19, supporting our hypothesis. Yet, because fear of COVID-19 did not influence anti-COVID-19 behavior, fear of COVID-19 could not mediate a link between the individual impact of the pandemic and antiCOVID-19 behavior.

\section{Change in Prejudice}

On average, prejudice did not increase over the studied six months, and fear of COVID19 did not enhance prejudice on the intra-individual level. This finding is especially important for theories that make direct predictions about the impact of fear of a virus on prejudice such as the BIS model (Meleady et al., 2021; Schaller \& Park, 2011). One reason for not supporting the BIS could be an incorrect assumption rooted in the evolutionary perspective, namely that outgroups are associated with the spreading of a virus. For instance, the pathogen-prevalence hypothesis implies that prejudice should increase when pathogens become more prevalent and 
more dangerous, as in the case of a pandemic. Avoiding outgroups is supposed to help to isolate oneself from those who are seen as more likely transmitters of foreign pathogens (Faulkner et al., 2004; Murray et al., 2011, 2013).

Moreover, we found no support for the expectation based on the intergroup threat theory (Stephan et al., 2009), whereby people could perceive increased intergroup competition over limited resources during the pandemic or fear of the transmission of the virus from the outgroup, resulting in a link between fear of COVID-19 and prejudice. The determined lack of association between fear of COVID-19 and prejudice could indicate that the ethnic outgroups that we researched were not linked to fear of COVID-19, which could be different in other contexts when, for instance, ethnic groups are used as scapegoats. Resources that alleviate the burdens of the pandemic might not have become a source of intergroup tension, at least in the researched contexts, and, thus, fear of COVID-19 did not relate to prejudice. The non-existent effect of fear on prejudice in our research is in line with evidence presented in the historical review of the link between pandemics and prejudice, which found that the consequences of pandemics ranged from having no apparent effect on intergroup relations to massive violence against outgroups (Cohn, 2015). Yet, it is possible that a pandemic could still be misused for awakening dormant prejudice or as an excuse for intergroup conflict (Huo, 2020). This could mean that a pandemic leads to an increase in prejudice only under certain conditions. For instance, Becker and colleagues (2011) found that threat elicited by the 2008 financial crisis led to an increase in prejudice only if the crisis was causally attributed to the outgroup.

A combination of literature on health-oriented behaviors and intergroup processes provides insights into how fear of a virus shapes prejudice and behaviors that should limit the virus transmission. In both cases, fear of COVID-19 did not lead to an increase in the outcome. 
Thus, fear of COVID-19 did not increase the undesirable outcome - prejudice, nor the desirable outcome - anti-COVID-19 behavior. Prior literature argued that self-efficacy might be necessary for fear to stimulate health-oriented behavior, otherwise, fear could even negatively impact on health-oriented behavior (Peters et al., 2013). However, there is no reason to expect that fear coupled with self-efficacy would positively affect prejudice, illustrating a different function of fear of the virus across literature on health-oriented behavior and intergroup processes.

We found the only significant, albeit small, relationship between initial levels of prejudice and fear of COVID-19; the more fear of COVID-19 participants initially expressed, the higher prejudice they reported. In studies that do not distinguish the intra- from the interindividual effects, such a significant link between initial levels of prejudice and fear of COVID19 could mask a non-existent intra-individual influence of fear of COVID-19 on prejudice. Our data indicated that prejudice did not automatically increase due to the pandemic or due to fear of COVID-19.

Prejudice was affected only by intergroup contact in the expected directions; positive direct and mass-mediated contact reduced prejudice, while negative direct and mass-mediated contact increased prejudice (Barlow et al., 2012; Graf \& Sczesny, 2019; Paluck et al., 2018; Pettigrew \& Tropp, 2006; Schiappa et al., 2005; Zingora et al., 2020; Zingora \& Graf, 2019). The effects of direct and mass-mediated contact were of a similar size, suggesting that massmediated contact could be an efficient substitute for direct contact in times when the frequency of direct contact is reduced. This applied to prejudice against immigrants from the Middle East across five countries as well as prejudice against Vietnamese people in the Czech Republic. The effects of intergroup contact were small, however, their cumulative effect over a longer period of time could bring about desired and more substantial change in prejudice. A cumulative effect of 
intergroup contact on prejudice could be especially important in the context of a pandemic when direct intergroup contact becomes less frequent (Meleady et al., 2021). Effects of contact experienced during or even prior to the pandemic could carry over a longer period of time, cumulate, and shape a change in prejudice in the longer term. We did not find that fear of the pandemic exacerbated prejudice, thus, we cannot claim that positive intergroup contact protected against negative effects of the pandemic on prejudice. Nevertheless, our findings enrich the evidence about the intra-individual effects of intergroup contact on prejudice, especially in circumstances when the frequency of contact is reduced, as in the case of a pandemic.

The exacerbating effect of negative intergroup contact through mass-media on prejudice during the pandemic calls for a careful presentation of ethnic minorities and other outgroups in mass media during such a crisis. During the COVID-19 pandemic, interpersonal contact in general and intergroup contact in particular was reduced (Meleady et al., 2021), making massmedia a more relevant source of information about outgroups. Whereas previous research documented that direct positive contact is usually more frequent than direct negative contact (Graf et al., 2014), this ratio is mostly reversed in the case of mass mediated contact, with negative content prevailing over positive content especially in the case of the news (in postconflict societies: Rupar et al., 2022; with respect to immigrants: Visintin et al., 2017). Consequently, when direct positive contact becomes rarer during crises such as the COVID-19 pandemic, it is especially important that mass media balance negative and positive information about outgroups.

Unexpectedly, the strongest predictor of anti-COVID-19 behavior-anti-COVID-19 norms - also increased prejudice. This means that behavior aimed at stopping COVID-19 observed in participants social environment increased their prejudice. Future research should 
investigate the potential negative side-effect effects of using social norms to promote desirable behavior on prejudice. This finding was not hypothesized; we can only speculate that social norms can make group membership salient, and as a consequence, the salient boundaries between groups enhance prejudice.

\section{Limitations}

Regarding limitations of our findings, we accounted for potential cross-cultural differences, including data from five European countries, but we did not collect representative samples. The pandemic could differently affect people from various social groups, especially in countries with high economic or social inequalities. Second, although we applied advanced modelling for disentangling intra- from inter-individual effects, our results should be interpreted with caution regarding causality. Third, we tracked the trajectory of and relations between variables during the first six months of the pandemic. As the pandemic has developed over a longer span, the reported effects may have changed. Fourth, concerning prejudice, we have focused on one of the most vulnerable and stigmatized groups in the current European contextmigrants from the Middle East who have entered Europe in large numbers since 2015 — and extended our finding to the less stigmatized ethnic group — Vietnamese people in the Czech Republic. Future research should test prejudice against other relevant outgroups.

\section{Conclusion}

All in all, the COVID-19 pandemic that has affected all countries around the world in an unprecedented manner represents an immense challenge for governments and state institutions. One of the challenges is the lack of information on how to motivate behaviors that can prevent the spreading of COVID-19; while protecting vulnerable social groups beyond the direct effects of the pandemic. Using an advanced analytical approach, our study brings important insights into 
the role of social norms in guiding adequate behaviors that should limit virus transmission and the role of intergroup contact and mass media in shaping prejudice in the context of the pandemic. Our results indicate that fear of a virus did not lead to the desirable increase in behaviors that should limit virus transmission during a pandemic, but it also did not bring about an undesirable increase in prejudice. This implies that fear of a virus is not an efficient tool in motivating anti-COVID-19 behavior. Although prior research indicated that fear coupled with self-efficacy could increase anti-COVID-19 behavior (Jørgensen et al., 2021), it is questionable how effectively self-efficacy could be induced along with the fear of the virus. In the context of the pandemic, one's ability to avoid the virus depends on the actions of others, which could limit the perception of being self-efficacious in avoiding the virus. This contrasts with the widespread use of inducing fear of COVID-19 in, for instance, campaigns directed to promote anti-COVID19 behavior (Stolow et al., 2020). Since fear of the virus does not enhance behavior that should counter the virus transmission, other strategies should be considered. Specifically, based on our findings, we propose that descriptive social norms about the functional behavior of others in one's social environment become the central foci of future research as well as strategies aimed at inducing health-promoting behavior in the context of pandemics. Importantly, we found that positive direct intergroup contact, even when experienced before the pandemic, represents a promising tool for challenging prejudice during the pandemic, while negative direct contact exacerbates prejudice towards outgroups. Social contact in general and direct intergroup contact in particular, could become scarcer during the pandemic (Meleady et al., 2021), highlighting the crucial influence of news about outgroup members from the mass-media on prejudice. Critically, mass-mediated intergroup contact comprises both positive and negative information, and, 
consequently, people working in mass media should be aware of and take responsibility for the widespread risk of exacerbating prejudice in their audience.

\section{Author Contributions}

All authors contributed to the study design and data collection. Data preparation and analysis were performed by T. Zingora and D. Lacko. T. Zingora drafted the manuscript. All authors provided critical revisions and approved the final version of the manuscript for submission. 


\section{References}

Adam-Troian, J., \& Bagci, S. C. (2021). The pathogen paradox: Evidence that perceived COVID-19 threat is associated with both pro- And anti-immigrant attitudes. International Review of Social Psychology, 34(1), 1-15. https://doi.org/10.5334/irsp.469

Alston, L., Meleady, R., \& Seger, C. R. (2020). Can past intergroup contact shape support for policies in a pandemic? Processes predicting endorsement of discriminatory Chinese restrictions during the COVID-19 crisis. Group Processes and Intergroup Relations. https://doi.org/10.1177/1368430220959710

Arslan, R. C., Walther, M. P., \& Tata, C. S. (2020). formr : A study framework allowing for automated feedback generation and complex longitudinal experience-sampling studies using R. 376-387.

Barlow, F. K., Hornsey, M. J., Hayward, L. E., Houkamau, C. A., Kang, J., Milojev, P., \& Sibley, C. G. (2019). Why Do We Hold Mixed Emotions About Racial Out-Groups? A Case for Affect Matching. Psychological Science, 30(6), 917-929. https://doi.org/10.1177/0956797619844269

Barlow, F. K., Paolini, S., Pedersen, A., Hornsey, M. J., Radke, H. R. M., Harwood, J., Rubin, M., \& Sibley, C. G. (2012). The Contact Caveat: Negative Contact Predicts Increased Prejudice More Than Positive Contact Predicts Reduced Prejudice. Personality and Social Psychology Bulletin, 38(12), 1629-1643. https://doi.org/10.1177/0146167212457953

Bavel, J. J. V., Baicker, K., Boggio, P. S., Capraro, V., Cichocka, A., Cikara, M., Crockett, M. J., Crum, A. J., Douglas, K. M., Druckman, J. N., Drury, J., Dube, O., Ellemers, N., Finkel, E. J., Fowler, J. H., Gelfand, M., Han, S., Haslam, S. A., Jetten, J., ... Willer, R. (2020). Using social and behavioural science to support COVID-19 pandemic response. Nature Human 
Behaviour, 4(5), 460-471. https://doi.org/10.1038/s41562-020-0884-z

Becker, J. C., Wagner, U., \& Christ, O. (2011). Consequences of the 2008 financial crisis for intergroup relations: The role of perceived threat and causal attributions. Group Processes and Intergroup Relations, 14(6), 871-885. https://doi.org/10.1177/1368430211407643

Block, P., Hoffman, M., Raabe, I. J., Dowd, J. B., Rahal, C., Kashyap, R., \& Mills, M. C. (2020). Social network-based distancing strategies to flatten the COVID 19 curve in a postlockdown world. Nature Human Behaviour. https://doi.org/10.1038/s41562-020-0898-6

Chen, F. F. (2007). Sensitivity of goodness of fit indexes to lack of measurement invariance. Structural Equation Modeling, 14(3), 464-504. https://doi.org/10.1080/10705510701301834

Christ, O., Schmid, K., Lolliot, S., Swart, H., Stolle, D., Tausch, N., Ramiah, A. Al, Wagner, U., Vertovec, S., \& Hewstone, M. (2014). Contextual effect of positive intergroup contact on outgroup prejudice. Proceedings of the National Academy of Sciences of the United States of America, 111(11), 3996-4000. https://doi.org/10.1073/pnas.1320901111

Cohn, S. K. (2015). Pandemics: waves of disease, waves of hate from the Plague of Athens to A.I.D.S. 85(June 2011), 535-555. https://doi.org/10.1111/j.14682281.2012.00603.x.Pandemics

Croucher, S. M., Nguyen, T., \& Rahmani, D. (2020). Prejudice Toward Asian Americans in the Covid-19 Pandemic: The Effects of Social Media Use in the United States. Frontiers in Communication, 5(June). https://doi.org/10.3389/fcomm.2020.00039

Daniels, C., DiMaggio, P., Mora, G. C., \& Shepherd, H. (2021). Has Pandemic Threat Stoked Xenophobia How COVID-19 Influences California Voters .pdf. Sociological Forum, 36(4). https://doi.org/10.1111/socf.12750 
Drouhot, L. G., Petermann, S., Schönwälder, K., \& Vertovec, S. (2021). Has the Covid-19 pandemic undermined public support for a diverse society? Evidence from a natural experiment in Germany. Ethnic and Racial Studies, 44(5), 877-892.

https://doi.org/10.1080/01419870.2020.1832698

Epstein, J. M., Parker, J., Cummings, D., \& Hammond, R. A. (2008). Coupled contagion dynamics of fear and disease: Mathematical and computational explorations. PLoS ONE, 3(12). https://doi.org/10.1371/journal.pone.0003955

European Commission. (2018). Special Eurobarometer 469: Integration of immigrants in the European Union (Issue April 2018).

European Commission. (2021). The EU's 2021-2027 long-term budget and NextGenerationEU. https://op.europa.eu/en/publication-detail/-/publication/d3e77637-a963-11eb-958501aa75ed71a1/language-en

Faulkner, J., Schaller, M., Park, J. H., \& Duncan, L. A. (2004). Evolved disease-avoidance mechanisms and contemporary xenophobic attitudes. Group Processes and Intergroup Relations, 7(4), 333-353. https://doi.org/10.1177/1368430204046142

Feldman, S., \& Stenner, K. (1997). Perceived threat and authoritarianism. Political Psychology, 18(4), 741-770. https://doi.org/10.1111/0162-895X.00077

Ferrer, E., Balluerka, N., \& Widaman, K. (2008). Factorial Invariance and The Specification of Second-Order Latent Growth Models. Methodology, 4(1), 22-36. https://doi.org/10.1027/1614-2241.4.1.22

Fincher, C. L., \& Thornhill, R. (2008). Assortative sociality, limited dispersal, infectious disease and the genesis of the global pattern of religion diversity. Proceedings of the Royal Society B: Biological Sciences, 275(1651), 2587-2594. https://doi.org/10.1098/rspb.2008.0688 
Fritsche, I., Jonas, E., \& Kessler, T. (2011). Collective Reactions to Threat: Implications for Intergroup Conflict and for Solving Societal Crises. Social Issues and Policy Review, 5(1), 101-136. https://doi.org/10.1111/j.1751-2409.2011.01027.x

Giannakakis, A. E., \& Fritsche, I. (2011). Social identities, group norms, and threat: On the malleability of ingroup bias. Personality and Social Psychology Bulletin, 37(1), 82-93. https://doi.org/10.1177/0146167210386120

Graf, S., Paolini, S., \& Rubin, M. (2014). Negative intergroup contact is more influential, but positive intergroup contact is more common: Assessing contact prominence and contact prevalence in five Central European countries. European Journal of Social Psychology, 44(6), 536-547. https://doi.org/10.1002/ejsp.2052

Graf, S., \& Sczesny, S. (2019). Intergroup contact with migrants is linked to support for migrants through attitudes, especially in people who are politically right wing. International Journal of Intercultural Relations, 73(August), 102-106. https://doi.org/10.1016/j.ijintrel.2019.09.001

Graf, S., Rubin, M., Assilamehou-Kunz, Y., Bianchi, M., Carnaghi, A., Fasoli, A., Finell, E., Gustafsson Sendén, M., Shamloo, S., Tocik, J., Lacko, D., \& Sczesny, S. (2022). Migrants, asylum seekers, and refugees: Different labels for immigrants influence attitudes through perceived benefits in nine countries. Manuscript under review.

Håkansson, A., \& Claesdotter, E. (2021). Fear of COVID-19, compliance with recommendations against virus transmission, and attitudes towards vaccination in Sweden. Heliyon, 8(December 2021), e08699. https://doi.org/10.1016/j.heliyon.2021.e08699

Hale, T., Angrist, N., Goldszmidt, R., Kira, B., Petherick, A., Phillips, T., Webster, S., Cameronblake, E., Hallas, L., Majumdar, S., \& Tatlow, H. (2020). A global panel database of 
pandemic policies (Oxford COVID-19 Government Response Tracker). Nature Human Behaviour. https://doi.org/10.1038/s41562-021-01079-8

Hamaker, E. L., Kuiper, R. M., \& Grasman, R. P. P. P. (2015). A critique of the cross-lagged panel model. Psychological Methods, 20(1), 102-116. https://doi.org/10.1037/a0038889

Hardin, C. D., \& Conley, T. D. (2001). A relational approach to cognition: Shared experience and relationship affirmation in social cognition. In Cognitive social psychology: \{The\} \{Princeton\} \{Symposium\} on the \{Legacy\} and \{Future\} of \{Social\} \{Cognition\} (pp. 3-17). Lawrence Erlbaum Associates Publishers.

Harmon-Jones, E., \& Mills, J. (2019). An introduction to cognitive dissonance theory and an overview of current perspectives on the theory. In E. Harmon-Jones (Ed.), Cognitive dissonance: Reexamining a pivotal theory in psychology (pp. 3-24). American Psychological Association. https://doi.org/10.1037/0000135-001

Harper, C. A., Satchell, L. P., Fido, D., \& Latzman, R. D. (2020). Functional Fear Predicts Public Health Compliance in the COVID-19 Pandemic Craig.

Harwood, J., Paolini, S., Joyce, N., Rubin, M., \& Arroyo, A. (2011). Secondary transfer effects from imagined contact: Group similarity affects the generalization gradient. British Journal of Social Psychology, 50(1), 180-189. https://doi.org/10.1348/014466610X524263

Hasell, J., Mathieu, E., Beltekian, D., Macdonald, B., Giattino, C., Ortiz-Ospina, E., Roser, M., \& Ritchie, H. (2020). A cross-country database of COVID-19 testing. Scientific Data, 7(1), 1-7. https://doi.org/10.1038/s41597-020-00688-8

Hounkpatin, H. O., Boyce, C. J., Dunn, G., \& Wood, A. M. (2018). Modeling bivariate change in individual differences: Prospective associations between personality and life satisfaction. Journal of Personality and Social Psychology, 115(6), e12-e29. 
https://doi.org/10.1037/pspp0000161

Hu, Z., Yang, Z., Li, Q., Zhang, A., \& Huang, Y. (2020). Infodemiological Study on COVID-19 Epidemic and COVID-19 Infodemic. March.

https://doi.org/10.20944/preprints202002.0380.v2

Huo, Y. (2020). Prejudice and discrimination. In J. Jetten, S. D. Reicher, S. A. Haslam, \& T. Cruwys (Eds.), Together apart: The psychology of COVID-19 (pp. 113-118). Los Angeles, CA: Sage.

Jackson, J. C., Van Egmond, M., Choi, V. K., Ember, C. R., Halberstadt, J., Balanovic, J., Basker, I. N., Boehnke, K., Buki, N., Fischer, R., Fulop, M., Fulmer, A., Homan, A. C., Van Kleef, G. A., Kreemers, L., Schei, V., Szabo, E., Ward, C., \& Gelfand, M. J. (2019). Ecological and cultural factors underlying the global distribution of prejudice. PLoS ONE, 14(9). https://doi.org/10.1371/journal.pone.0221953

Jakovljevic, M., Bjedov, S., Jaksic, N., \& Jakovljevic, I. (2020). Covid-19 pandemia and public and global mental health from the perspective of global health security. Psychiatria Danubina[revista en internet] 2020 [acceso 25 de agosto del 2020]; 31(1): 6-14. 32(1), 614. https://doi.org/10.24869/psyd.2020.6

Jonas, E., Martens, A., Kayser, D. N., Fritsche, I., Sullivan, D., \& Greenberg, J. (2008). Focus Theory of Normative Conduct and Terror-Management Theory: The Interactive Impact of Mortality Salience and Norm Salience on Social Judgment. Journal of Personality and Social Psychology, 95(6), 1239-1251. https://doi.org/10.1037/a0013593

Jørgensen, F., Bor, A., \& Petersen, M. B. (2021). Compliance without fear: Individual-level protective behaviour during the first wave of the COVID-19 pandemic. British Journal of Health Psychology, 26, 679-696. https://doi.org/https://doi.org/10.1111/bjhp.12519 
Kievit, R. A., Brandmaier, A. M., Ziegler, G., van Harmelen, A. L., de Mooij, S. M. M., Moutoussis, M., Goodyer, I. M., Bullmore, E., Jones, P. B., Fonagy, P., Lindenberger, U., \& Dolan, R. J. (2018). Developmental cognitive neuroscience using latent change score models: A tutorial and applications. Developmental Cognitive Neuroscience, 33(October 2017), 99-117. https://doi.org/10.1016/j.den.2017.11.007

Kim, H. S., Sherman, D. K., \& Updegraff, J. A. (2016). Fear of Ebola: The Influence of Collectivism on Xenophobic Threat Responses. Psychological Science, 27(7), 935-944. https://doi.org/10.1177/0956797616642596

Klopack, E. T., \& Wickrama, K. (2020). Modeling Latent Change Score Analysis and Extensions in Mplus: A Practical Guide for Researchers. Structural Equation Modeling, 27(1), 97-110. https://doi.org/10.1080/10705511.2018.1562929

Kok, G., Bartholomew, L. K., Parcel, G. S., Gottlieb, N. H., \& Fernandez, M. E. (2014). Finding theory-and evidence-based alternatives to fear appeals Intervention Mapping (pp. 98-107). https://doi.org/10.1002/ijop.12001

Kok, G., Peters, G. J. Y., Kessels, L. T. E., ten Hoor, G. A., \& Ruiter, R. A. C. (2018). Ignoring theory and misinterpreting evidence: the false belief in fear appeals. Health Psychology Review, 12(2), 111-125. https://doi.org/10.1080/17437199.2017.1415767

Legate, N. (2022). A global experiment on motivating social distancing during the COVID-19 pandemic. 1-11. https://doi.org/10.1073/pnas.2111091119/-/DCSupplemental.Published

Li, T., \& Wang, Z. (2022). Disaggregating the between-person and within-person associations between peer acceptance and academic achievement in early elementary school. Journal of Applied Developmental Psychology, 78(May 2021), 101357.

https://doi.org/10.1016/j.appdev.2021.101357 
Makhanova, A., Plant, E. A., Ketterman, A. B., \& Maner, J. K. (2022). Evolution and Human Behavior Pathogen threat and intergroup prejudice using the minimal group paradigm : Evidence from a registered report. Evolution and Human Behavior, March. https://doi.org/10.1016/j.evolhumbehav.2022.05.002

Mandalaywala, T. M., Gonzalez, G., \& Tropp, L. R. (2020). Early perceptions of COVID-19 intensity and anti-Asian prejudice among White Americans Tara. Preprint.

Mani, A., Mullainathan, S., Shafir, E., \& Zhao, J. (2013). Poverty impedes cognitive function. Science, 341(6149), 976-980. https://doi.org/10.1126/science.1238041

Meleady, R., Hodson, G., \& Earle, M. (2021). Person and situation effects in predicting outgroup prejudice and avoidance during the COVID-19 pandemic. Personality and Individual Differences, 172(October 2020), 110593. https://doi.org/10.1016/j.paid.2020.110593

Mertens, G., Gerritsen, L., Duijndam, S., Salemink, E., \& Engelhard, I. M. (2020). Fear of the coronavirus (COVID-19): Predictors in an online study conducted in March 2020. Journal of Anxiety Disorders, 74(April), 102258. https://doi.org/10.1016/j.janxdis.2020.102258

Murray, D. R., Schaller, M., \& Suedfeld, P. (2013). Pathogens and Politics: Further Evidence That Parasite Prevalence Predicts Authoritarianism. PLoS ONE, 8(5). https://doi.org/10.1371/journal.pone.0062275

Murray, D. R., Trudeau, R., \& Schaller, M. (2011). On the origins of cultural differences in conformity: Four tests of the pathogen prevalence hypothesis. Personality and Social Psychology Bulletin, 37(3), 318-329. https://doi.org/10.1177/0146167210394451

Paluck, E. L., Green, S. A., \& Green, D. P. (2018). The contact hypothesis re-evaluated. Behavioural Public Policy, 1-30. https://doi.org/10.1017/bpp.2018.25

Paolini, S., Harwood, J., Rubin, M., Husnu, S., Joyce, N., \& Hewstone, M. (2014). Positive and 
extensive intergroup contact in the past buffers against the disproportionate impact of negative contact in the present. European Journal of Social Psychology, 44(6), 548-562. https://doi.org/10.1002/ejsp.2029

Peters, G. J. Y., Ruiter, R. A. C., \& Kok, G. (2013). Threatening communication: A critical reanalysis and a revised meta-analytic test of fear appeal theory. Health Psychology Review, 7(SUPPL1). https://doi.org/10.1080/17437199.2012.703527

Petherick, A., Goldszmidt, R., Andrade, E. B., Furst, R., Hale, T., Pott, A., \& Wood, A. (2021). A worldwide assessment of changes in adherence to COVID-19 protective behaviours and hypothesized pandemic fatigue. Nature Human Behaviour, 5(9), 1145-1160. https://doi.org/10.1038/s41562-021-01181-X

Pettigrew, T. F., \& Tropp, L. R. (2006). A meta-analytic test of intergroup contact theory. Journal of Personality and Social Psychology, 90(5), 751-783. https://doi.org/10.1037/0022-3514.90.5.751

Prati, G., \& Pietrantoni, L. (2016). Knowledge, Risk Perceptions, and Xenophobic Attitudes: Evidence from Italy During the Ebola Outbreak. Risk Analysis, 36(10), 2000-2010. https://doi.org/10.1111/risa.12537

Pyszczynski, T., Lockett, M., Greenberg, J., \& Solomon, S. (2021). Terror Management Theory and the COVID-19 Pandemic. Journal of Humanistic Psychology, 61(2), 173-189. https://doi.org/10.1177/0022167820959488

Riek, B. M., Mania, E. W., \& Gaertner, S. L. (2006). Intergroup Threat and Outgroup Attitudes: A Meta-Analytic Review. Personality and Social Psychology Review, 10(4), 336-353. https://doi.org/10.1207/s15327957pspr1004_4

Rosseel, Y. (2012). lavaan : an R package for structural equation modeling and more Version 0. 
5-12 ( BETA ). 12.

Rupar, M., Graf, S., \& Voca, Sh. (2022). Contact with former adversaries through mass-media is linked to forgiveness after dyadic and multiethnic conflicts. Manuscript accepted for publication. European Journal of Social Psychology. Manuscript accepted for publication.

Rzymski, P., \& Nowicki, M. (2020). COVID-19-related prejudice toward Asian medical students: A consequence of SARS-CoV-2 fears in Poland. Journal of Infection and Public Health, 13(6), 873-876. https://doi.org/10.1016/j.jiph.2020.04.013

Schaller, M., \& Neuberg, S. L. (2012). Danger, Disease, and the Nature of Prejudice(s). In Advances in Experimental Social Psychology (1st ed., Vol. 46). Elsevier Inc. https://doi.org/10.1016/B978-0-12-394281-4.00001-5

Schaller, M., \& Park, J. H. (2011). The Behavioral Immune System ( and Why It Matters ). https://doi.org/10.1177/0963721411402596

Schiappa, E., Gregg, P. B., \& Hewes, D. E. (2005). The parasocial contact hypothesis. Communication Monographs, 72(1), 92-115. https://doi.org/10.1080/0363775052000342544

Sep, M. S. C., Steenmeijer, A., \& Kennis, M. (2019). The relation between anxious personality traits and fear generalization in healthy subjects: A systematic review and meta-analysis. Neuroscience and Biobehavioral Reviews, 107(September), 320-328. https://doi.org/10.1016/j.neubiorev.2019.09.029

Stephan, W. G., Ybarra, O., \& Morrison, K. R. (2009). Intergroup threat theory. In T. D. Nelson (Ed.), Handbook of prejudice, stereotyping, and discrimination. (pp. 43-59). US: Psychology Press.

Stolow, J. A., Moses, L. M., Lederer, A. M., \& Carter, R. (2020). How Fear Appeal Approaches 
in COVID-19 Health Communication May Be Harming the Global Community. Health Education and Behavior, 47(4), 531-535. https://doi.org/10.1177/1090198120935073

Stussi, Y., Brosch, T., \& Sander, D. (2015). Learning to fear depends on emotion and gaze interaction: The role of self-relevance in fear learning. Biological Psychology, 109, 232238. https://doi.org/10.1016/j.biopsycho.2015.06.008

Tabri, N., Hollingshead, S. J., \& Wohl, M. J. A. (2020). Framing Covid-19 as an Existential Threat predicts Anxious Arousal and Prejudice. Preprint.

Terry, D. I., \& Hogg, M. A. (1996). Group norms and the attitude-behavior relationship: A role for group identification.

TNS Medium Gallup. (2017). TNS Medium Gallup Attitudes towards the Impact of the Refugee and Migrant Crisis in Serbia's Municipalities. August.

Tsai, J.-Y., Phua, J., Pan, S., \& Yang, C. (2020). Intergroup Contact, COVID-19 News Consumption, and the Moderating Role of Digital Media Trust on Prejudice Toward Asians in the United States: Cross-Sectional Study. Journal of Medical Internet Research, 22(9), e22767. https://doi.org/10.2196/22767

Vandenberg, R., \& Lance, C. (2000). A Review and Synthesis of the Measurement Invariance Literature: Suggestions, Practices, and. Organizational Research Methods, 3(1), 4-70. http://orm.sagepub.com/cgi/content/abstract/3/1/4

White, F. A., Borinca, I., Vezzali, L., Reynolds, K. J., Blomster Lyshol, J. K., Verrelli, S., \& Falomir-Pichastor, J. M. (2020). Beyond direct contact: The theoretical and societal relevance of indirect contact for improving intergroup relations. Journal of Social Issues, October 2020, 132-153. https://doi.org/10.1111/josi.12400

Witte, K., \& Allen, M. (2000). A meta-analysis of fear appeals: Implications for effective public 
health campaigns. Health Education and Behavior, 27(5), 591-615.

https://doi.org/10.1177/109019810002700506

Yamagata, M., Teraguchi, T., \& Miura, A. (2020). The Relationship between InfectionAvoidance Tendency and Exclusionary Attitudes towards Foreigners: A Case Study of the COVID-19 Outbreak in Japan. 1-36. https://doi.org/10.31234/osf.io/vhrqn

Zeng, G., Wang, L., \& Zhang, Z. (2020). Prejudice and xenophobia in COVID-19 research manuscripts. Nature Human Behaviour, 4(9), 879. https://doi.org/10.1038/s41562-02000948-y

Zingora, T., \& Graf, S. (2019). Marry who you love: Intergroup contact with gay people and another stigmatized minority is related to voting on the restriction of gay rights through threat. Journal of Applied Social Psychology, 49(11), 684-703. https://doi.org/10.1111/jasp.12627

Zingora, T., Vezzali, L., \& Graf, S. (2020). Stereotypes in the face of reality : Intergroup contact inconsistent with group stereotypes changes attitudes more than stereotype-consistent contact. Group Processes \& Intergroup Relations. https://doi.org/10.1177/1368430220946816 